\title{
1 KIF21A influences breast cancer metastasis and survival
}

2 Anton J. Lucanus ${ }^{1}$, Victoria King ${ }^{2}$, George W. Yip ${ }^{2}$

$3{ }^{1}$ School of Anatomy, Human Biology and Physiology, the University of Western Australia,

4 Crawley, WA, Australia

$5{ }^{2}$ Department of Anatomy, Yong Loo Lin School of Medicine, National University of

6 Singapore, Singapore

7 Corresponding Author: George W. Cheong Yip ${ }^{2}$

8 Email address: george_yip@nuhs.edu.sg

9

10 ABSTRACT

11 Breast cancer pathogenesis is known to be propagated by the differential expression of a

12 group of proteins called the Kinesin Superfamily (KIFs), which are instrumental in the

13 intracellular transport of chromosomes along microtubules during mitosis. During mitosis,

14 KIFs are strictly regulated through temporal synthesis so that they are only present when

15 needed. However, their misregulation may contribute to uncontrolled cell growth due to

16 premature sister chromatid separation, highlighting their involvement in tumorigenesis. One

17 particular KIF, KIF21A, was recently found to promote the survival of human breast cancer

18 cells in vitro. However, how KIF21A influences other cancerous phenotypes is currently

19 unknown. This study therefore aimed to consolidate the in vitro role of KIF21A in breast

20 cancer metastasis, while also analysing KIF21A expression in human breast cancer tissue to

21 determine its prognostic value. This was achieved by silencing KIF21A in MCF-7 and MDA- 
22 MB-231 breast cancer cell lines via siRNA transfection. Migration, invasion, proliferation,

23 and adhesion assays were then performed to measure the effects of KIF21A silencing on

24 oncogenic behaviour. Immunohistochemistry was also conducted in 263 breast cancer tissue

25 samples to compare KIF21A expression levels against various prognostic outcomes and

26 clinicopathological parameters. KIF21A knockdown reduced cell migration (by $42.8 \%$

27 [MCF-7] and 69.7\% [MDA-MB-231]) and invasion (by 72.5\% [MCF-7] and 42.5\% [MDA-

28 MB-231]) in both cell lines, but had no effect on adhesion or proliferation, suggesting that

29 KIF21A plays an important role in the early stages of breast cancer metastasis. Unexpectedly

30 however, KIF21A was shown to negatively correlate with various pro-malignant

31 clinicopathological parameters, including tumour size and histological grade, and high

32 KIF21A expression predicted better breast cancer survival (hazard ratio $=0.45$ ), suggesting

33 that KIF21A is a tumour suppressor. The conflicting outcomes of in vitro and in vivo data

34 may be due to the possible multi-functionality of KIF21A or study limitations, and means no

35 definitive conclusions can be drawn about the role of KIF21A in breast cancer. This warrants

36 further investigation, which may prove pivotal to the development of novel chemotherapeutic

37 strategies to mediate KIF21A's function and enhance prognostic outcomes.

\section{INTRODUCTION}

Breast cancer is the most frequently diagnosed cancer among women [1], and its metastasis

41 often leads to death in patients. Breast cancer pathogenesis is known to be affected by the

42 differential expression of a group of proteins called the kinesin superfamily (KIF) [2].

43 Kinesins were first isolated from squid tissue and identified as molecular motors for axonal transport that are ubiquitous in all eukaryotes [3]. In total, 45 kinesins have been identified in 
46 differences, however all share a highly-conserved motor domain that provides motor binding

47 to microtubules [6]. They have adenosine triphosphate (ATP) activity and microtubule-

48 dependent motion potential, allowing movement along microtubules through coupling energy

49 from ATP hydrolysis to force production [6].

50 The role of kinesins has since been specified in the transport of vesicles and organelles within

51 cells, and chromosomes during mitosis and meiosis. During mitosis, kinesins are strictly

52 regulated through temporal synthesis so that they are only present when needed [7].

53 However, misregulation of kinesins during the cell cycle may contribute to uncontrolled cell

54 growth, highlighting their involvement in tumorigenesis. For example, either the depletion or

55 overexpression of some mitotic kinesins can lead to unbalanced movement of chromosomes

56 along microtubules during mitosis [8]. This causes a cascade of excessive spindle separation,

57 premature sister chromatid separation, overshooting before anaphase, and finally unequal

58 distribution of DNA and aneuploidy [9-11]. The aneuploid daughter cells may display

59 cancerous behaviour, including increased metastatic behaviour [12].

60 Furthermore, Some KIFs have recently been associated with poor prognosis [13-18] and

61 chemotherapeutic drug resistance [19-21] in breast cancer patients and cell lines, respectively.

62 Such an involvement in mitotic deregulation, clinical outcomes and chemotherapeutic

63 resistance in breast cancer highlights the importance of understanding the molecular

64 mechanisms underlying the behaviour of KIFs.

65 One particular KIF, KIF21A, was recently found to promote lysosomal stability and the 66 survival of human breast cancer cells in vitro [22]. However, how KIF21A distinctly affects

67 other malignant phenotypes and prognostic outcomes in breast cancer is currently unknown.

68 This study therefore aimed to (1) identify whether KIF21A is overexpressed in breast cancer

69 tissue; (2) understand the functional behaviour of KIF21A in breast cancer cell lines and (3) 
evaluate the associations between KIF21A expression levels and breast cancer recurrence,

71 survival and various clinicopathological parameters. KIF21A functional behaviour was

72 assessed via migration, invasion, proliferation, and adhesion assays in KIF21A-silenced

73 versus wildtype breast cancer cell lines. Immunohistochemistry staining of KIF21A in

74 clinical IDC breast tissue microarrays was then performed to determine KIF21A expression

75 in breast cancer tissue and to examine relationships between KIF21A expression,

76 clinicopathological data and prognostic outcomes. We hypothesised that KIF21A shows

77 upregulated expression in breast cancer tissue and correlates with poor prognostic outcomes,

78 and KIF21A enhances pro-cancerous phenotypes in vitro, including migration, invasion,

79 proliferation and adhesion. Identifying exactly how KIF21A is involved in breast

80 carcinogenesis may prove pivotal to the development of chemotherapeutic targeting to

81 mediate its function and improve prognostic outcomes.

82

83

84 2. MATERIALS AND METHODS

85

\subsection{Cell Culture}

MCF-7 (ATCC: HTB-22, VA, USA) and MDA-MB-231 (ATCC: HTB-2) cell lines were

87 cultured in Dulbecco's Modified Eagle Medium (DMEM) supplemented with $10 \%$ fetal

88 bovine serum (FBS) (Hyclone, Logan, UT, USA) and Roswell Park Memorial Institute

89 medium 1640 (RPMI 1640) (Hyclone) supplemented with 10\% FBS, respectively. Both cell

90 lines were incubated at $37^{\circ} \mathrm{C}$ in a humidified incubator with $5 \% \mathrm{CO}_{2}$. All cell culture was

91 done without antibiotics.

92

$93 \quad$ 2.2 Small Interfering RNA (siRNA) Transfection 
94 Conditions used to achieve favourable silencing efficiency in both cell lines were as follows:

$951 \times 10^{5}(\mathrm{MCF}-7)$ or $2 \times 10^{5}$ (MDA-MB-231) cells per well were seeded with culture medium

96 in a 6-well plate and incubated for 24 hours, which enabled the cells to reach at least $30 \%$

97 confluence. Transfection with Ambion Silencer Select siRNA (Ambion, Foster City, CA,

98 USA; Table 1) was performed using Oligofectamine (Thermo Fisher Scientific, Wilmington,

99 DE, USA) in Opti-MEM1 Reduced Serum Medium (Thermo Fisher Scientific). For MCF-7

100 cells, $10 \mu \mathrm{L}$ siRNA was mixed with $175 \mu \mathrm{L}$ Opti-MEM1 in one tube, while $5 \mu \mathrm{L}$

101 Oligofectamine was mixed with $10 \mu \mathrm{L}$ Opti-MEM1 in another tube. For MDA-MB-231 cells,

$10210 \mu \mathrm{L}$ siRNA was mixed with $100 \mu \mathrm{L}$ Opti-MEM1 in one tube, while $10 \mu \mathrm{L}$ Oligofectamine

103 was mixed with $100 \mu \mathrm{L}$ Opti-MEM1 in another tube. The tubes were incubated at room

104 temperature for five minutes, after which the contents of both were mixed and incubated

105 again at room temperature for a further 20 minutes. The medium in each well of the 6-well

106 plate was removed and replaced with $800 \mu \mathrm{L}$ (MCF-7) or $780 \mu \mathrm{L}$ (MDA-MB-231) Opti-

107 MEM1 and $200 \mu \mathrm{L}$ (MCF-7) or $220 \mu \mathrm{L}$ (MDA-MB-231) of the previously-incubated siRNA-

108 Oligofectamine mixture. The plate was then left to incubate for 8 hours at $37{ }^{\circ} \mathrm{C}$ in a 109 humidified incubator with $5 \% \mathrm{CO}_{2} .500 \mu \mathrm{L}$ culture medium (30\% FBS) was then added to

110 each well. At 24 hours post-transfection, the medium was replaced with fresh medium

111 (supplemented with 10\% FBS). At 48 hours post-transfection, cells were harvested from each

112 well for use in subsequent experiments. Ambion Silencer Select Scrambled siRNA was used

113 as the negative control and Ambion Silencer Select GAPDH siRNA was used as the positive 114 control.

\section{$116 \quad 2.3$ RNA Extraction and One-step qRT-PCR}

117 Total RNA was extracted using the Direct-zol RNA MiniPrep Kit (Zymo Research, Irvine, 118 CA, USA) according to manufacturer's instructions. RNA yield and purity were then 
119 quantified using the Nanodrop ND-100 Spectrophotometer (Thermo Fisher Scientific)

120 according to manufacturer's protocol. Extracted RNA was subjected to one-step qRT-PCR

121 using the iTaq Universal SYBR Green One-Step Kit (Bio-Rad, Hercules, CA, USA),

122 following manufacturer's instructions, on the CFX96 Touch Real-Time PCR Detection

123 System (Bio-Rad). The qRT-PCR primers used for this study (1st BASE, Singapore) are

124 shown in Table 2. The program settings used for qRT-PCR were: (1) reverse transcription at

$12550{ }^{\circ} \mathrm{C}$ for 10 minutes; (2) activation step at $95{ }^{\circ} \mathrm{C}$ for 30 seconds; (3) 45 cycles of

126 denaturation at $95^{\circ} \mathrm{C}$ for 5 seconds and annealing at $60^{\circ} \mathrm{C}$ for 30 seconds; and (4) melt curve

127 analysis.

128

$129 \quad 2.4$ Western Blotting

130 Protein was isolated from cells 72 hours post-transfection using M-PER Mammalian Protein

131 Extraction Reagent (200 $\mu \mathrm{L} /$ well) (Thermo Fisher Scientific) mixed with $10 \mu \mathrm{g} / \mathrm{mL}$ Halt

132 Protease Inhibitor Cocktail ( $2 \mu \mathrm{L} /$ well) and EDTA ( $2 \mu \mathrm{L} /$ well $)$ (Thermo Fisher Scientific).

133 The buffer mixture was added to cells and incubated for 5 minutes on ice. Cells were then

134 scraped off with a cell scraper (TPP, Trasadingen, Switzerland), aspirated, and centrifuged at

$13516,000 \mathrm{~g}$ for 10 minutes at $4{ }^{\circ} \mathrm{C}$. The resulting supernatant was extracted and stored at $-80{ }^{\circ} \mathrm{C}$.

136 Following extraction, protein samples were quantified using the Bicinchoninic Acid (BCA)

137 Protein Assay Kit (Thermo Fisher Scientific) according to manufacturer's protocol and

138 sodium dodecyl sulphate polyacrylamide gel electrophoresis (SDS-PAGE) was performed.

139 Following the SDS-PAGE run, protein samples were transferred onto a polyvinylidene

140 fluorise (PVDF) membrane (Millipore, Billerica, MA, USA) via the wet transfer method.

141 Protein was subsequently transferred at $100 \mathrm{~V}$ for 1 hour at $4{ }^{\circ} \mathrm{C}$. The membrane was then

142 blocked with 5\% BSA (Sigma-Aldrich) in 1X Tris-Buffered Saline and 1\% Tween 20

143 (TBST) for 2 hours, and incubated at $4{ }^{\circ} \mathrm{C}$ overnight with primary antibodies (Table 4.3) that 
144 were diluted in 5\% BSA. Primary antibodies were then removed and the membrane was

145 washed with $1 \mathrm{X}$ TBST three times for 10 minutes each time. Secondary antibodies (Table

146 4.3) were then added and incubated for 1 hour at room temperature. After which, the

147 membrane was washed with 1X TBST three times for 10 minutes each time.

\section{$149 \quad 2.5$ Transwell Migration Assay}

150 Migration assays were performed using Costar $6.5 \mathrm{~mm}$ Transwell chambers with $8.0 \mu \mathrm{m}$ pore 151 polycarbonate membrane inserts (Corning, Lowell, MA, USA). siRNA transfection was 152 performed as per section 4.2. 48 hours post-transfection, cells were harvested, resuspended in 153 fresh medium (10\% FBS), and $5 \times 10^{4}$ (MCF-7) or $3 \times 10^{4}$ (MDA-MB-231) cells were seeded 154 into the inserts. The medium outside the inserts was $600 \mu \mathrm{L}$ fresh medium supplemented with $30 \%$ FBS. The plate was then left in an incubator for 24 hours at $37^{\circ} \mathrm{C}$. Cell suspension was then removed from inside the inserts. Migrated cells on the outer surface of the

157 membrane of the inserts were subsequently fixed by $100 \%$ methanol and stained with $0.5 \%$ $158(\mathrm{w} / \mathrm{v})$ crystal violet indicator (Sigma-Aldrich). Visualisation of the migrated cells was 159 performed using a 10X objective lens under a Nikon SMZ1500 stereomicroscope coupled to 160 a Nikon DXM1200F digital camera (Nikon, Minato, Tokyo, Japan). Five random field 161 images per insert were captured for quantification.

\section{$163 \quad$ 2.6 Matrigel Invasion Assay}

164 The invasion assay was performed in a similar manner to the migration assay, although the 165 chambers used were BD BioCoat Matrigel Invasion Chambers with $8.0 \mu \mathrm{m}$ pore size inserts 166 (BD Biosciences, San Jose, CA, USA). siRNA transfection was performed as per section 4.2. 16748 hours post-transfection, cells were harvested, resuspended in fresh medium (10\% FBS), 168 and $1 \times 10^{5}$ (MCF-7) or $5 \times 10^{4}$ (MDA-MB-231) cells were seeded into the inserts. The 
169 medium on the outside of the inserts was $600 \mu \mathrm{L}$ fresh culture medium, supplemented with

$17030 \%$ FBS. The plate was left in an incubator for 24 hours at $37^{\circ} \mathrm{C}$. Invaded cells were then

171 fixed, stained, imaged and quantified in an identical manner to the migration assay.

172

\section{2.7 Serum-Starved Proliferation Assay}

174 Proliferation assays were performed using the CellTiter 96 Aqueous One Solution Cell 175 Proliferation Assay (Promega, Fitchburg, WI, USA). To begin, cells were serum-starved

176 overnight prior to seeding, i.e. sub-cultured in fresh medium in a $25-\mathrm{cm}^{2}$ flask without FBS.

177 siRNA transfection was performed as per section 4.2. 72 hours post-transfection, culture 178 medium was removed and replaced with $1.8 \mathrm{~mL}$ fresh medium (10\% FBS) with $300 \mu \mathrm{L}$ MTS 179 reagent. Samples were incubated at $37^{\circ} \mathrm{C}$ for 1 hour prior to measuring absorbance values 180 once every hour for 4 hours. Formazan absorbance was detected at $490 \mathrm{~nm}$ by a GENios 181 Plate Reader (Tecan, Austria).

\subsection{Cell Adhesion Assay}

183 96-well plates were coated overnight with either $50 \mu \mathrm{L}$ collagen I (Corning) or $50 \mu \mathrm{L}$ 184 fibronectin (BD Biosciences), both at concentrations of $20 \mu \mathrm{g} / \mathrm{mL}$. Collagen I and fibronectin 185 were then removed and the wells were washed twice with 1X PBS. $100 \mu \mathrm{L} \mathrm{1 \%} \mathrm{BSA} \mathrm{(Sigma-}$ 186 Aldrich) was then added to the same wells for 1 hour at room temperature for blocking. BSA 187 was then removed and the wells were washed twice with 1X PBS. siRNA transfection was 188 performed as per section 4.2. 48 hours post-transfection, cells were harvested, resuspended 189 with fresh medium and seeded into the wells at a density of $1 \times 10^{4}$ cells for collagen I and 3 $190 \times 10^{4}$ cells for fibronectin wells. The 96-well plate was then incubated for 60 minutes at 37

$191{ }^{\circ} \mathrm{C}$ for cells to adhere. Subsequently, non-adhered cells were washed off by 1X PBS. $100 \mu \mathrm{l}$ 192 complete medium and $20 \mu \mathrm{l}$ MTS were then added to each well. Formazan absorbance was 193 detected at $490 \mathrm{~nm}$ by a GENios Plate Reader (Tecan) once every hour for 4 hours. 


\subsection{Immunohistochemistry (IHC)}

196 Archived, formalin-fixed, paraffin-embedded breast cancer tissue samples were received

197 from the Department of Pathology, Singapore General Hospital (SGH). Only breast invasive 198 ductal carcinoma (IDC) cases were used for this study. A total of 287 breast IDC cases from 1991997 to 2007 were analysed, including 263 tumour tissue samples and 24 adjacent normal 200 counterparts (all female). For the full distribution of clinicopathological data see Table 4. The 201 collection of human tissue samples for this study received ethical approval from the 202 Institutional Review Board, Singapore General Hospital.

204 Slides were prepared using tissue microarray (TMA) technology. The TMA slides were deparaffinised twice in Clearene (Leica Biosystems), rehydrated in a graded series of ethanol, and finally washed in distilled water. The slides were then washed in $1 \mathrm{X}$ Tris-buffered saline (TBS) (Bio-Rad), incubated with 3\% hydrogen peroxide for 30 minutes to block endogenous peroxidase activity, and washed in $1 \mathrm{X}$ TBS with $1 \%$ Triton X-100 (TBS-TX) (Bio-Rad) thrice. Antigen retrieval was performed by boiling the slides at $100{ }^{\circ} \mathrm{C}$ for 20 minutes in a $500 \mathrm{~mL}$ solution containing $0.1 \mathrm{M}$ sodium citrate, $0.1 \mathrm{M}$ citric acid and distilled water. After

211 cooling to room temperature, the slides were washed in 1X TBS-TX three times. They were 212 then blocked for 1 hour using 1:100 dilution goat serum (Dako, Agilent Technologies, 213 Denmark) at room temperature, followed by KIF21A primary antibody (1:100 dilution; Table 214 2) incubation overnight at $4{ }^{\circ} \mathrm{C}$. The next day, the slides were washed in $1 \mathrm{X}$ TBS-TX, then 215 incubated with undiluted horseradish peroxidase (HRP) conjugated secondary antibodies 216 (polyclonal goat anti-rabbit immunoglobulins, Dako, catalogue no. K4010) for 1 hour at 217 room temperature, and washed again in $1 \mathrm{X}$ TBS-TX. To visualise the staining, the slides 218 were incubated with 3,3'-Diaminobenzidine (DAB) (Thermo Fisher Scientific) for 30 
219 minutes, followed by counter-staining in filtered concentrated Shandon Harris haematoxylin

220 (Thermo Fisher Scientific) for 30 seconds. The slides were finally dehydrated in a graded

221 series of ethanol and washed twice in Clearene, followed by fixing in Permount (Thermo

222 Fisher Scientific).

223

224 The fixed TMA slides were scanned and their staining intensities assessed using Philips

225 Image Management System software (Philips, Amsterdam, Netherlands). KIF21A immuno-

226 positivity was scored independently by one individual followed by confirmation by a trained

227 pathologist. The scoring criteria was based on KIF21A staining intensities with '0' = no

228 staining, ' $1+$ ' = weak staining intensity, ' $2+$ ' $=$ moderate staining intensity, and ' $3+$ ' $=$ strong

229 staining intensity. Weighted average intensity (WAI) was then calculated, which is the

230 average intensity of each stained cell

\section{$232 \quad 2.10$ Statistical Analysis}

233 For qRT-PCR and all functional assays, Prism 5 (GraphPad Software, La Jolla, CA, USA) was used to conduct statistical analysis. One-way ANOVAs were utilised to detect significant differences $(p<0.05)$ between wildtype cells and two groups of KIF21A-silenced cells (each group used a different siRNA sequence), followed by Tukey's multiple comparisons post-hoc

237 test. Immunohistochemistry results were analysed using SPSS 18.0 for Windows (SPSS Inc.,

238 Chicago, IL, USA). KIF21A immunostaining in malignant versus normal tissues were 239 compared using the non-parametric Mann-Whitney test. Relationships between KIF21A 240 immunoscores and nominal clinicopathological parameters were analysed using Fisher's 241 exact test, while relationships with ordinal parameters were analysed using Kendall's tau-c 242 test. For the survival analyses (recurrence and mortality), the timeline measures (in months) were: (1) OS (Overall survival) $=$ Date of Death - Date of Diagnosis; (2) SAR (Survival after 
244 Recurrence) $=$ Date of Death - Date of Recurrence; (3) DFS (Disease free survival) $=$ Date of

245 Recurrence - Date of Diagnosis. Survival analyses were performed using Kaplan-Meier

246 analysis and the log-rank (Mantel-Cox) test, and variables that achieved statistical

247 significance in univariate analyses $(p<0.05)$ were subsequently entered into a multivariate

248 analysis using the Cox proportional hazards model via the backward stepwise regression

249 method (Model A). In addition, to examine the predictive value of KIF21A expression in

250 greater detail, the analysis included a multivariate Cox proportional hazards model that

251 included all clinicopathological parameters via the enter method (Model B; Table 5.5).

252 Statistical significance was set at $p<0.05$ for all tests.

253

\section{RESULTS}

\subsection{KIF21A Silencing in Breast Cancer Cell Lines}

qRT-PCR analysis showed KIF21A was significantly silenced using two different siRNA sequences, siKIF21A-1 and siKIF21A-2 in MCF-7 cells by $39.8 \%(p<0.01)$ and $73.8 \%(p<$ $0.001)$, respectively, and in MDA-MB-231 cells by $67.8 \%(p<0.001)$ and $62.7 \%(p<0.01)$, respectively (Figures 1A,B). Western blot analysis showed silencing via siKIF21A-1 and siKIF21A-2 translated to a reduction in protein levels in MCF-7 cells by $41.8 \%(p<0.05)$ $69.7 \%(p<0.01)$, respectively (Figures 1 C,D).

\subsection{Transwell Migration Assay}

264 KIF21A silencing in MCF-7 resulted in a $42.8 \%(p<0.01)$ and $39.8 \%(p<0.01)$ decrease in 265 the average number of migrated cells for siKIF21A-1 and siKIF21A-2 groups, respectively, 266 compared to the negative control (Figures 2A,B). KIF21A silencing in MDA-MB-231 267 reduced cell migration by $69.7 \%(p<0.0001)$ and $64.6 \%(p<0.001)$ for siKIF21A-1 and 
268 siKIF21A-2, respectively, compared to the negative control (Figures 2C,D).

\section{3.3 Matrigel Invasion Assay}

270 KIF21A silencing in MCF-7 resulted in a $42.5 \%(p<0.001)$ and $72.5 \%(p<0.0001)$ decrease

271 in the average number of invaded cells for siKIF21A-1 and siKIF21A-2 groups, respectively,

272 compared to the negative control (Figures 3A,B). KIF21A silencing in MDA-MB-231

273 reduced cell invasion by $42.5 \%(p<0.05)$ and $41.0 \%(p<0.05)$ for siKIF21A-1 and

274 siKIF21A-2, respectively, compared to the negative control (Figures 3C,D).

\section{$275 \quad 3.4$ Cell Proliferation Assay}

276 Analysis of cell proliferation showed no significant differences in cell proliferation between

277 the negative and KIF21A-silenced groups for both MCF-7 and MDA-MB-231 cells (Figures $2784 \mathrm{~A}, \mathrm{~B})$.

279

\subsection{Cell Adhesion Assay}

281 For MCF-7 cells, analysis showed no significant differences in cell adhesion to both collagen

282 I and fibronectin between the negative and KIF21A-silenced groups (Figures 4C,D). For 283 MDA-MB-231 cells, KIF21A silencing also had no significant effect on cell adhesion to 284 collagen I (Figure 4E). Interestingly, however, silenced MDA-MB-231 cells displayed 285 reduced adhesion to fibronectin by $47.2 \%(p<0.05)$ and $54.0 \%(p<0.05)$ for siKIF21A-1 286 and siKIF21A-2, respectively (Figure 4F).

3.6 Comparison of KIF21A Staining Between Normal and Tumorous Breast IDC

Tissues

KIF21A staining was predominately observed in the nucleus of both normal and tumourous

290 breast epithelial cells, while cytoplasmic staining was either absent or minimal (Figure 
291 5A,B,C). Analysis showed no significant differences in KIF21A nuclear staining between

292 tumour and normal samples (Figure 5D).

293

294 3.7 Relationship Between KIF21A Expression and Clinicopathological Parameters in

295 Breast IDC Tissues

296 Cut-off values above and below the mean WAI (1.0) were determined as "high" and "low" 297 KIF21A expression, respectively. High KIF21A expression correlated with tumour size 298 below $20 \mathrm{~mm}(p<0.05)$, and progressively lower histological grades $(p<0.01$; Table 5). No 299 significant correlations were observed between KIF21A and other parameters.

\subsection{Univariate (Kaplan-Meier) analysis of survival and KIF21A expression}

301 The three timelines investigated were overall survival (OS), survival after recurrence (SAR), 302 and disease-free survival (DFS). Survival data is cause-specific and was available for all 303 cases, with a follow-up period ranging from 0 months to 156 months. It should be noted that no patients survived after breast cancer recurrence for the entire follow-up period (Table 6).

305 Surprisingly, Kaplan-Meier analysis showed patients with high nuclear KIF21A expression 306 were more likely to have better overall survival $(p<0.05$; Figure 6A) and survival after 307 recurrence $(p<0.05$; Figure 6B). However, nuclear KIF21A expression was not identified as 308 a significant predictor of breast cancer recurrence, as measured by DFS (Figure 6C).

3.9 Multivariate (Cox proportional hazards regression) analysis of survival and KIF21A expression

311 Variables that achieved statistical significance in univariate analyses $(p<0.05)$ were 312 subsequently entered into a multivariate analysis using Cox proportional hazards model via

313 the backward stepwise regression method (Model A; Table 7). In addition, to examine the 
314 prognostic value of KIF21A in greater detail, the analysis included a multivariate Cox

315 proportional hazards model that included all clinicopathological parameters via the enter

316 method (Model B; Table 7). This included patients' age, race, tumour size, histological grade,

317 lymph node involvement, lymphovascular invasion, and ER, PR and HER2 statuses.

318 However, only those which showed statistical significance $(p<0.05)$ are shown in Table 7.

319 Model A showed KIF21A acts independently to predict SAR $(p<0.05)$, but significantly

320 correlates with tumour size in predicting OS $(p<0.05)$. Model B predicted KIF21A as an

321 independent prognostic factor for both OS $(p<0.05)$ and SAR $(p<0.05)$. However, both

322 models showed KIF21A expression was not a prognostic factor for recurrence, as measured

323 by DFS.

\section{4. DISCUSSION}

\section{4.1 KIF21A Mediates Breast Cancer Metastasis In Vitro}

327 This study identifies KIF21A as a protein whose depletion consistently caused a statistically

328 and biologically significant reduction in breast cancer cell migration and invasion in vitro

329 (Figures 2 and 3). To our knowledge, this is the first study to identify the role of KIF21A in

330 cancer cell metastasis - an important finding in the assessment of KIF21A as a potential

331 therapeutic target. Invasion of malignant cells into the surrounding ECM and migration of

332 invaded cells towards the bloodstream are pivotal early steps in metastasis, suggesting that

333 KIF21A is an important mediator of early carcinogenesis. The observed migratory influence

334 of KIF21A was enhanced in MDA-MB-231 cells, which are known to be highly metastatic,

335 while higher silencing efficiency using siKIF21A-2 in MCF-7 intensified the reduction in

336 migration. Furthermore, although a more optimal silencing efficiency would be preferred to

337 observe the full effects of KIF21A knockdown, there was still a significant reduction in both 
338 invasion and migration. Whether complete knockdown would have accentuated this

339 observation remains unknown. Nonetheless, these cumulative findings suggest that KIF21A

340 may be a key component of breast cancer cell migratory and invasive pathways. This could

341 be explained by its interaction with other molecules and their known mechanisms (see

342 Section 4.3 below).

343 However, these observations surprisingly contradicted the in vivo findings of KIF21A

344 expression in human breast cancer tissue (discussed in-detail in Section 4.2), meaning that

345 KIF21A's role in cancer metastasis is largely inconclusive. Despite this, in vitro functional

346 assays do serve an important purpose. Although they are only representative of complex in

347 vivo conditions, they provide a critical understanding about the influence of genes on distinct

348 metastatic components. In this case, KIF21A was shown to influence the distinct metastatic

349 components of migration and invasion - a phenomenon supported by studies of other kinesin

350 family members. KIF3A and KIF3B, for example, have been shown to interact in a complex

351 that transports proteins essential for cancer cell migration [23], while KIF11 has been found

352 to respond to directional cues during chemotaxis to govern the direction of MDA-MB-231

353 cell migration [24]. Other studies identify KIF14 [25], KIF2A [26], and KIF18A [27] as

354 mediators of breast cancer migration in vitro via a range of pathways. Given the discrepant

355 results of the current study, migration and invasion assays should be extended to in vivo

356 models to elucidate KIF21A's precise role in these processes.

357 Following migration, cancer cells must adhere to the ECM of a new site where they can then

358 rapidly proliferate. This study investigated the role of KIF21A in this process. KIF21A

359 knockdown by 40-70\% did not induce any changes in cell proliferation for both breast cancer

360 cell lines (Figure 4), and thus KIF21A is not implicated as a player in breast cell

361 proliferation. Although it is difficult to identify studies reporting similarly negative results for 
362 other kinesin family members, the present study shows KIF21A varies from previous reports

363 of KIFs acting as key mediators of proliferation in breast cancer [26,28].

364 KIF21A was also tested for cell adhesion to collagen I and fibronectin fibers - both protein

365 components of the ECM - yet no changes were observed following silencing in MCF-7 for

366 both fibers, and in MDA-MB-231 for collagen I fibers (Figure 4). However, reduced

367 adhesion to fibronectin did occur in MDA-MB-231 cells, suggesting KIF21A could facilitate

368 breast cancer cell establishment in foreign sites, particularly for highly invasive cells. The

369 fundamental genetic differences between MCF-7 and MDA-MB-231 cells may have

370 contributed to differences with their adhesion assays. Further analysis is thus required to

371 investigate the functional role of KIF21A in breast cancer cell adhesion, which could be done

372 via overexpression studies and other adhesion assays involving laminin, gelatin and collagen

373 II fibers. More broadly, there is no particular commonality in the adhesive capabilities of

374 other kinesins, with many being shown to either positively or negatively regulate adhesion in

375 various cell lines $[25,29,30]$. Further studies in KIF21A are therefore encouraged.

\section{$376 \quad 4.2$ Disparity Between In Vitro and In Vivo Results}

377 The present study suggested KIF21A exerts oncogenic activity in vitro, which resonates with

378 our hypothesis and previous studies that show KIF21A facilitates the survival of breast

379 cancer cell lines [22]. However, conflicting results were obtained in vivo.

380 Immunohistochemical analysis suggested KIF21A exerts tumour-suppressive functions,

381 rather than oncogenic activity. Although it is unclear why different results were obtained for

382 the same gene, there are several explanations for this phenomenon: (1) ethnic differences.

383 Various studies illustrate that the mutation status of numerous genes contributing to breast

384 cancer is different between Asian and Caucasian populations. This study was predominately

385 performed in Asian individuals, while MCF-7 cells and MDA-MB-231 cells were isolated 
386 from Caucasian women. Ethnicity may therefore be a contributing factor to any

387 discrepancies, and in vivo studies of KIF21A in Caucasian populations are encouraged. (2)

388 One molecule may have dual or multiple physiological functions. For example, both 389 transforming growth factor beta (TGF-beta) and signal transducer and activator of 390 transcription 3 (STAT3) have oncogenic or tumour-suppressive roles depending on different 391 conditions including the mutational background of the tumor [31-33]. Whether KIF21A has a 392 dual effect remains unknown, however similarly conflicting studies have been observed in 393 other kinesins, particularly KIF14, which has been shown to both promote and suppress 394 tumorigenesis [15,34]. (3) Study limitations. In vitro assays are useful in studying the 395 influence of various molecules on distinct metastatic components, but we must not forget the amazingly complex story of the tumour microenvironment. Firstly, despite strict conditions,

397 cell line studies cannot control for the vast array of biological parameters that would 398 otherwise be present in vivo. Cell lines studies are therefore better used as tools to delineate 399 the molecular events underpinning carcinogenesis rather than predicting the entire metastatic 400 cascade. Secondly, cell lines are only representative of one individual. Although two breast cancer cell lines were used for support in this study, they cannot match the statistical power of the 263 breast IDC patient samples analysed via IHC. Of course, some patients may have indeed had a poorer prognosis with high KIF21A expression, which would resonate with the

404 in vitro findings. However, there was a significant trend towards poorer prognosis correlating 405 with low KIF21A expression. Further in vitro analyses are therefore encouraged in more breast cancer cell lines that are subject to both KIF21A silencing and overexpression.

\subsection{KIF21A Signaling Pathways Leading to Cell Migration and Invasion}

409 Although few studies have investigated KIF21A beyond its role in congenital fibrosis of the 410 extraocular muscles type-1 (CFEOM1), evidence suggests it may interact with other genes 
411 involved in cell migration. KIF21A binds to brefeldin A (BFA)-inhibited guanine nucleotide-

412 exchange factor (BIG1) [35] to maintain the organisation of the Golgi apparatus [36], and

413 also transports KN motif and ankyrin repeat domains 1 (KANK1), influencing its membrane

414 localisation [37]. Subsequent exploration revealed that both BIG1 and KANK1 co-

415 immunoprecipitated with KIF21A and each other, such that they may act as a scaffold in

416 KIF21A-powered intracellular transport [38]. The interaction between all three molecules

417 was shown to affect cell migration; a phenomenon explained by their combined effects on

418 cell polarity. Generation and maintenance of cell polarity is essential for directional migration

419 and results from asymmetric membrane traffic achieved by intracellular transport and the

420 delivery of extra membrane to the cell's leading edge $[39,40]$. KIF21A is theorised to act via

421 BIG1 and KANK1 to position the Golgi and microtubule-organising center (MTOC)

422 structures anterior to the nucleus, resulting in a polarity shift that induces front-end-directed

423 cell migration [38]. This interaction would explain the observations seen in breast cancer cell

424 migration in the present study. In support of this theory, previous studies show polarisation of

425 Golgi and MTOC structures to be explicitly disturbed by KANK1 or BIG1 siRNA treatment

426 [38]. However, further investigation is required to identify additional players in

427 KIF21A/BIG1/KANK1 functional interactions and to elucidate the detailed molecular

428 mechanisms that alter cell polarity to influence directional migration.

\section{$430 \quad$ 4.4 KIF21A in Breast Cancer Tissues}

431 Although our in vitro data strongly supported a tumorigenic role for KIF21A in breast cancer,

432 IHC in breast cancer tissue microarrays was contrary to our hypothesis and showed KIF21A

433 associated with anti-malignant phenotypes and a better prognosis. Both analyses suggest

434 KIF21A is involved in breast cancer pathogenesis and prognosis, however their conflicting 435 outcomes mean the overall results of this study remain largely inconclusive. 
436 Nonetheless, numerous important findings came from the IHC analysis. Firstly, there were no 437 significant differences in KIF21A expression between breast IDC samples and adjacent

438 normal tissues (Figure 5). This adds to inconsistent evidence regarding the role of KIF21A in 439 breast oncogenesis, and is contradictory to previous studies in the kinesin superfamily, which 440 observe upregulation of numerous KIFs in breast cancer $[13,15,17]$. KIF21A may therefore 441 not be a useful diagnostic biomarker.

443 In addition, KIF21A expression was shown to negatively correlate with the pro-malignant 444 phenotypes of large tumour size $(\geq 20 \mathrm{~mm})$ and high histological grade (Table 5). Large 445 tumour size and high histological grade classically predict poorer prognosis in breast cancer 446 [41], so KIF21A may exert a tumour-suppressive role during breast carcinogenesis. However, 447 the mechanism via which it performs this role was not clear from the IHC analysis, as 448 KIF21A displayed no relationships with lymphovascular invasion, lymph node involvement, 449 or various receptors including ER, PR, and HER2. This suggests KIF21A may not regulate 450 distant metastasis to lymph nodes and blood vessels (in contradiction to the in vitro observations), and it may not be involved in the mechanisms through which oestrogen, 452 progesterone and human epidermal growth factor increase breast cell proliferation. This 453 differs from previous observations of concerted KIF21A upregulation upon the introduction 454 of exogenous oestrogen in vitro [42]. One explanation for KIF21A-induced tumour 455 suppression may therefore be its role in mitosis (see Section 4.5 below).

457 Survival analyses were also performed, and revealed high KIF21A expression predicted 458 better OS and SAR, but had no significant associations with DFS (Figure 6). KIF21A may 459 therefore act as a tumour suppressor, and may be used as a predictor of breast cancer 460 survival, but not recurrence. To identify whether KIF21A predicted survival independently of 
461 other clinicopathological parameters, multivariate analyses were also performed (Table 7).

462 Although univariate analysis suggested KIF21A co-predicted OS and SAR with tumour size

463 and histological grade, Cox proportional hazards models revealed KIF21A acted

464 independently. KIF21A may therefore be an independent prognostic biomarker for better

465 breast cancer survival. In this study cohort, lymphovascular invasion, lymph node

466 involvement, and hormonal and growth factor receptor statuses had no correlations with SAR

467 and OS - a rare finding (although some of those variables did correlate with recurrence).

468 Nonetheless, this observation adds to evidence that KIF21A functions independently of

469 lymphovascular invasive pathways, oestrogen, progesterone, and human epidermal growth

470 factor to implement its tumour-suppressive activity.

471

472 The possible role of KIF21A as a tumour suppressor and predictor of better breast cancer

473 prognosis differs from that of most other kinesin family members. KIFs 2A [43], 2C [17], 3C

474 [44], and 26B [45] have all been identified as predictors of worse breast cancer prognosis.

475 Intriguingly however, a select few kinesins have been observed as tumour-suppressor genes

476 consistent with the results of the current study, albeit in other cancer types. Overexpression of

477 both KIF4 [46] and KIF14 [34] has been shown to reduce metastatic phenotypes in vitro and

478 predict better survival outcomes in human gastric carcinoma and lung adenocarcinoma,

479 respectively. In both cases, it was theorised that they carried out their tumour-suppressive

480 functions through their roles in mitosis - a phenomenon that could explain similar

481 observations in this study (see below).

482

483 4.5 Mitotic Misregulation as a Functional Explanation for KIF21A-mediated

484 Tumorigenesis

485 Errors at any point during the cell cycle can be catastrophic and in humans can lead to cancer 
486 [47]. Chromosome mis-segregation during mitosis, for example, results in abnormal 487 cytokinesis and aneuploidy [48], which is cleared in normal cells through apoptosis.

488 However, tumour cells show higher rates of aneuploidy, which is often associated with poor 489 clinical outcomes [49-51]. Interestingly, misregulation of various mitotic kinesins has been 490 shown to result in aneuploidy, because unbalanced movement of kinesins can cause excessive 491 spindle separation, premature sister chromatid detachment, overshooting before anaphase, 492 and eventually unequal distribution of DNA [8-11]. The aneuploid daughter cells could, 493 theoretically, display any possible tumorigenic phenotype and a plethora of metastatic 494 characteristics, including aberrant migration and invasion. Via this mechanism, KIF21A 495 depletion could result in aneuploidy to facilitate tumour formation, which explains the in vivo 496 findings of this study. High KIF21A expression may therefore suppress carcinogenesis if 497 KIF21A is implicated in mitosis.

\subsection{Future Work}

499 The results of this study were largely inconclusive due to discrepancies between in vitro and 500 clinical data. To further elucidate KIF21A's role in breast cancer, other functional analyses 501 should therefore be performed (e.g. apoptosis and drug resistance assays) in more breast 502 cancer cell lines that have been subjected to KIF21A knockdown, overexpression and the 503 introduction of exogenous KIF21A. This would solidify knowledge about KIF21A's role in 504 breast cancer in vitro, however there still remains little physiological evidence on the role of 505 KIF21A in vivo. IHC analysis of an Asian population in this study should therefore be 506 extended to Caucasian cohorts. Furthermore, given many known KIF proteins occur in mice 507 [4], they would be an ideal animal model to knockout genes and explore physiological effects 508 in tumour xenografts. KIF21A's biological pathways are also poorly understood, and could 509 be discovered through microarray analysis of KIF21A-silenced cells. Any upstream or 
510 downstream targets of KIF21A that are known breast cancer oncogenes would provoke

511 interesting follow-up studies, and have the potential to be targeted alongside KIF21A in

512 combinative therapy.

513 Because of the lack of primary data, KIF21A and many other kinesins are yet to be

514 considered therapeutic targets or prognostic predictors, despite common consensus that

515 kinesins play a vital role in breast carcinogenesis [8]. If mounting evidence supports either a

516 tumour-suppressive or oncogenic role for KIF21A in the metastatic cascade, its pathways

517 could be modulated through targeted chemotherapeutic strategies. Future studies should

518 therefore attempt to uncover the structure of KIF21A's ATP-, microtubule- and enzyme-

519 binding sequences, which could lead to the development of KIF21A inhibitors and enhancers.

520 Identifying binding partners has enormous therapeutic potential, because drugs that mimic

521 those partners could bind to allosteric pockets to either promote or suppress KIF21A and its

522 effects on carcinogenesis.

\section{$524 \quad 4.7$ Conclusions}

525 In summary, this study illustrates the potential involvement of KIF21A in breast cancer 526 pathogenesis and progression. However, the conflicting outcomes of in vitro and in vivo data

527 means no definitive conclusions can be drawn about KIF21A's role in breast cancer. This

528 may be due to ethnic differences, the possible multi-functionality of KIF21A, or even study

529 limitations, and warrants further investigation into the influence of KIF21A in vivo, the

530 molecules it interacts with, and its potential as a prognostic biomarker. Such knowledge

531 could lead to the development of novel chemotherapeutic strategies to mediate its function

532 and enhance prognostic outcomes. 


\section{TABLES}

\begin{tabular}{|c|c|c|}
\hline Gene Target & Target Sequence & Concentration Used \\
\hline KIF21A (Homo sapiens) & $5^{\prime}-$ & $10 \mathrm{nM}$ \\
& CCCUUACAGAAGCCCGAUAtt-3' & \\
KIF21A(Homo sapiens) & $\begin{array}{c}\text { G'- } \\
\text { GUAAGACCCAUGUCAGAUAtt- } \\
3^{\prime}\end{array}$ & $10 \mathrm{nM}$ \\
\hline
\end{tabular}

Table 1. siRNAs used and their corresponding target sequences. Two different KIF21A siRNA sequences were tested to ensure reliability in results.

\begin{tabular}{|c|l|l|c|}
\hline Gene & \multicolumn{1}{|c|}{ Forward Primer } & \multicolumn{1}{|c|}{ Reverse Primer } & \multicolumn{1}{|c|}{$\begin{array}{c}\text { Amplicon } \\
\text { Size (bp) }\end{array}$} \\
\hline KIF21A & $\begin{array}{l}5^{\prime}-\text { AATGCTGTCAGGATG } \\
\text { TGGGA-3' }\end{array}$ & $\begin{array}{l}\text { 5'-ACTCACAGTCCCAAGA } \\
\text { GCTC-3' }\end{array}$ & 186 \\
\hline \multirow{3}{*}{$\beta$-ACTIN } & $\begin{array}{l}5^{\prime}- \\
\text { TGGCACCACACCTTCTAC } \\
\text { AAT-3' }\end{array}$ & $\begin{array}{l}\text { 5'-GATAGCACAGCCTGGA } \\
\text { TAGCA-3' }\end{array}$ & 166 \\
\hline \multirow{3}{*}{ GAPDH } & $\begin{array}{l}\text { 5'- } \\
\text { GAAGGTGAAGGTCGGAG } \\
\text { TCAACG-3' }\end{array}$ & $\begin{array}{l}\text { 5'-TGCCATGGGTGGAATC } \\
\text { ATATTGG-3' }\end{array}$ & 157 \\
\hline
\end{tabular}

Table 2. Primer sequences used during qRT-PCR. 


\begin{tabular}{|c|c|c|c|c|c|}
\hline $\begin{array}{c}\text { Primary } \\
\text { antibody }\end{array}$ & $\begin{array}{c}\text { Catalogue } \\
\text { number }\end{array}$ & Dilution & $\begin{array}{c}\text { Secondary } \\
\text { antibody }\end{array}$ & $\begin{array}{c}\text { Catalogue } \\
\text { number }\end{array}$ & Dilution \\
\hline KIF21A & $\begin{array}{c}\text { Aviva Systems } \\
\text { ARP33932_P050 }\end{array}$ & $1: 1000$ & $\begin{array}{c}\text { Polyclonal } \\
\text { goat anti- } \\
\text { rabbit HRP }\end{array}$ & $\begin{array}{c}\text { Dako } \\
\text { P0448 }\end{array}$ & $1: 5,000$ \\
$\beta$-actin & $\begin{array}{c}\text { Sigma Aldrich } \\
\text { A2228 }\end{array}$ & $1: 10,000$ & $\begin{array}{c}\text { Anti-mouse } \\
\text { IgG HRP }\end{array}$ & $\begin{array}{c}\text { GE } \\
\text { Healthcare } \\
\text { NA9310 }\end{array}$ & $1: 15,000$ \\
\hline
\end{tabular}

Table 3. List of primary and secondary antibodies used in Western blotting and their dilutions. Detection of bound antibodies was performed using either the Pico or Femto Substrate Systems (Thermo Fisher Scientific). The resulting blots were scanned on X-ray films using a GS-800 Calibrated Imaging Densitometer (Bio-Rad). The optical densities of protein bands were analysed with Quantity One Version 4.1.1 software (Bio-Rad).

\begin{tabular}{|c|c|c|c|}
\hline $\begin{array}{l}\text { Clinicopathological } \\
\text { Feature }\end{array}$ & $\begin{array}{l}\text { Number of } \\
\text { Cases }(\%)\end{array}$ & $\begin{array}{l}\text { Clinicopathological } \\
\text { Feature }\end{array}$ & $\begin{array}{l}\text { Number of } \\
\text { Cases }(\%)\end{array}$ \\
\hline Age & & Race & \\
\hline$\leq 53 \mathrm{yrs}$ old & $149(56.7)$ & Chinese & $219(83.3)$ \\
\hline$>53 \mathrm{yrs}$ old & $114(43.3)$ & Non-Chinese & $44(16.7)$ \\
\hline Tumour size & & Lymphovascular invasion & \\
\hline$\leq 20 \mathrm{~mm}$ & $90(34.2)$ & No & $204(77.6)$ \\
\hline$>20 \mathrm{~mm}$ & $168(63.9)$ & Yes & $58(22.1)$ \\
\hline Not available & $5(1.9)$ & Not available & $1(0.4)$ \\
\hline Lymph node involvement & & Histological grade & \\
\hline No & $99(37.6)$ & Grade 1 & $40(15.2)$ \\
\hline Yes & $137(52.1)$ & Grade 2 & $102(38.8)$ \\
\hline \multirow[t]{2}{*}{ Not available } & $27(10.3)$ & Grade 3 & $114(43.3)$ \\
\hline & & Not available & $7(2.7)$ \\
\hline \multicolumn{4}{|l|}{ ER status } \\
\hline Negative & $87(33.1)$ & PR status & \\
\hline Positive & $172(65.4)$ & Negative & $126(47.9)$ \\
\hline \multirow[t]{2}{*}{ Not available } & $4(1.5)$ & Positive & $133(50.6)$ \\
\hline & & Not available & $4(1.5)$ \\
\hline \multicolumn{4}{|l|}{ HER2 status } \\
\hline Negative & $158(60.1)$ & & \\
\hline Positive & $61(23.2)$ & & \\
\hline Not available & $44(16.7)$ & & \\
\hline
\end{tabular}

Table 4. Distribution of Clinicopathological Data in Breast IDC Patients. Abbreviations: 


\begin{tabular}{|c|c|c|c|c|c|}
\hline \multirow{3}{*}{\multicolumn{2}{|c|}{ Clinicopathological Parameter }} & \multicolumn{3}{|c|}{ Weighted Average Index (WAI) } & \multirow{3}{*}{ p-value } \\
\hline & & $\leq 1.0$ & $>1.0$ & \multirow{2}{*}{$\begin{array}{c}\text { Cases with } \\
\text { no data }\end{array}$} & \\
\hline & & \multicolumn{2}{|c|}{ Number of valid cases (\%) } & & \\
\hline \multirow{2}{*}{ Age } & $\leq 53$ yrs old & $89(59.7)$ & $60(40.3)$ & \multirow{2}{*}{0} & \multirow{2}{*}{0.093} \\
\hline & $>53$ yrs old & $78(68.4)$ & $36(31.6)$ & & \\
\hline \multirow{2}{*}{ Race } & Chinese & $141(64.4)$ & $78(35.6)$ & \multirow{2}{*}{0} & \multirow{2}{*}{0.499} \\
\hline & Non-Chinese & $26(59.1)$ & $18(40.9)$ & & \\
\hline \multirow{2}{*}{ Tumour Size } & $\leq 20 \mathrm{~mm}$ & $49(54.4)$ & $41(45.6)$ & \multirow{2}{*}{5} & \multirow{2}{*}{$0.030 *$} \\
\hline & $>20 \mathrm{~mm}$ & $115(68.5)$ & $53(31.5)$ & & \\
\hline \multirow{2}{*}{$\begin{array}{l}\text { Lymphovascular } \\
\text { Invasion }\end{array}$} & No & $128(62.7)$ & $76(37.3)$ & \multirow{2}{*}{1} & \multirow{2}{*}{0.759} \\
\hline & Yes & $38(65.5)$ & $20(34.5)$ & & \\
\hline \multirow{2}{*}{$\begin{array}{l}\text { Lymph Node } \\
\text { Involvement }\end{array}$} & No & $63(63.6)$ & $36(36.4)$ & \multirow{2}{*}{27} & \multirow{2}{*}{0.577} \\
\hline & Yes & $93(67.9)$ & $44(32.1)$ & & \\
\hline \multirow{3}{*}{ Histological Grade } & Grade 1 & $19(47.5)$ & $21(52.5)$ & \multirow{3}{*}{7} & \multirow{3}{*}{$0.002^{* *}$} \\
\hline & Grade 2 & $63(61.8)$ & $39(38.2)$ & & \\
\hline & Grade 3 & $84(73.7)$ & $30(26.3)$ & & \\
\hline \multirow{2}{*}{ Oestrogen Receptor } & Negative & $56(64.4)$ & $31(35.6)$ & \multirow{2}{*}{4} & \multirow{2}{*}{0.892} \\
\hline & Positive & $108(62.8)$ & $64(37.2)$ & & \\
\hline \multirow{2}{*}{$\begin{array}{l}\text { Progesterone } \\
\text { Receptor }\end{array}$} & Negative & $83(65.9)$ & $43(34.1)$ & \multirow{2}{*}{4} & \multirow{2}{*}{0.440} \\
\hline & Positive & $81(60.9)$ & $52(39.1)$ & & \\
\hline \multirow{2}{*}{ HER2 } & Negative & $102(64.6)$ & $56(35.4)$ & \multirow{2}{*}{44} & \multirow{2}{*}{0.166} \\
\hline & Positive & $33(54.1)$ & $28(45.9)$ & & \\
\hline
\end{tabular}

ER: oestrogen receptor; PR: progesterone receptor; HER2: human epidermal growth factor receptor 2 .

Table 5. Clinicopathological parameters of breast IDC cases correlated against KIF21A expression in epithelial nucleus of tumour cells. Abbreviations: HER2: human epidermal growth factor receptor $2{ }^{*} \mathrm{p}<0.05, * * \mathrm{p}<0.01$ (Fisher's exact test for nominal parameters, Kendall's tau-c test for ordinal parameters).

\begin{tabular}{|c|c|c|c|c|c|c|}
\hline \multirow{2}{*}{ Timeline } & \multirow{2}{*}{$\begin{array}{c}\text { KIF21A } \\
\text { WAI }\end{array}$} & \multirow{2}{*}{ Total } & \multirow{2}{*}{$\begin{array}{l}\text { No. of } \\
\text { events }\end{array}$} & \multicolumn{2}{|c|}{ Censored } & \multirow{2}{*}{$\begin{array}{c}\text { Log-rank } p \\
\text { (Mantel-Cox) }\end{array}$} \\
\hline & & & & No. & Percent & \\
\hline \multirow{3}{*}{$\begin{array}{c}\text { Overall } \\
\text { Survival }\end{array}$} & $\leq 1.0$ & 166 & 43 & 123 & $74.1 \%$ & \multirow{3}{*}{$0.012^{*}$} \\
\hline & $>1.0$ & 96 & 12 & 84 & $87.5 \%$ & \\
\hline & Overall & 262 & 55 & 207 & $79.0 \%$ & \\
\hline \multirow{3}{*}{$\begin{array}{c}\text { Survival } \\
\text { After } \\
\text { Recurrence }\end{array}$} & $\leq 1.0$ & 67 & 43 & 25 & $37.3 \%$ & \multirow{3}{*}{$0.025^{*}$} \\
\hline & $>1.0$ & 31 & 12 & 21 & $67.7 \%$ & \\
\hline & Overall & 98 & 55 & 46 & $46.9 \%$ & \\
\hline \multirow{3}{*}{$\begin{array}{l}\begin{array}{c}\text { Disease- } \\
\text { free }\end{array} \\
\text { Survival }\end{array}$} & $\leq 1.0$ & 165 & 67 & 98 & $59.4 \%$ & \multirow{3}{*}{0.187} \\
\hline & $>1.0$ & 95 & 31 & 64 & $67.4 \%$ & \\
\hline & Overall & 260 & 98 & 162 & $62.3 \%$ & \\
\hline
\end{tabular}

Table 6. Data summary of nuclear KIF21A epithelial staining, cause-specific mortality (OS and SAR) and recurrence (DFS) in breast IDC patients over 156-month follow-up period. An event is defined as either cause-specific death (for OS and SAR timelines) or 


\begin{tabular}{|c|c|c|c|c|c|c|c|c|c|c|c|}
\hline \multirow{3}{*}{ Timeline } & \multirow{3}{*}{ Parameter } & \multirow{3}{*}{$\begin{array}{c}\text { Reference } \\
\text { Group }^{\mathrm{a}} \\
(\mathrm{HR}=1)\end{array}$} & \multirow{2}{*}{\multicolumn{3}{|c|}{ Univariate Analysisc }} & \multicolumn{6}{|c|}{ Multivariate Analyses } \\
\hline & & & & & & \multicolumn{3}{|c|}{ Model Ad } & \multicolumn{3}{|c|}{ Model Be } \\
\hline & & & HR & $95 \% \mathrm{CI}$ & $p$ value & HR & $95 \% \mathrm{CI}$ & $p$ value & HR & $95 \% \mathrm{CI}$ & $p$ value \\
\hline \multirow{3}{*}{$\begin{array}{c}\text { Overall } \\
\text { survival }\end{array}$} & $\begin{array}{l}\text { Tumour } \\
\text { Size }\end{array}$ & $\leq 20 \mathrm{~mm}$ & 2.91 & $\begin{array}{c}1.42- \\
5.96\end{array}$ & $0.002 * *$ & 2.55 & $\begin{array}{c}1.24- \\
5.25\end{array}$ & 0.011* & 2.20 & $\begin{array}{c}0.88- \\
5.50\end{array}$ & 0.090 \\
\hline & $\begin{array}{l}\text { Histological } \\
\text { Grade }\end{array}$ & Low $^{\mathrm{b}}$ & 1.67 & $\begin{array}{c}1.10- \\
2.54\end{array}$ & $0.012 *$ & 1.42 & $\begin{array}{c}0.91- \\
2.21\end{array}$ & 0.121 & 0.99 & $\begin{array}{c}0.57- \\
1.72\end{array}$ & 0.968 \\
\hline & KIF21A WAI & Low & 0.45 & $\begin{array}{c}0.24- \\
0.85\end{array}$ & $0.012 *$ & 0.39 & $\begin{array}{c}0.19- \\
0.81\end{array}$ & $0.012 *$ & 0.34 & $\begin{array}{c}0.14- \\
0.82\end{array}$ & $0.017^{*}$ \\
\hline \multirow{2}{*}{$\begin{array}{l}\text { Survival } \\
\text { after } \\
\text { recurrence }\end{array}$} & $\begin{array}{c}\text { Tumour } \\
\text { Size }\end{array}$ & $\leq 20 \mathrm{~mm}$ & 2.24 & $\begin{array}{l}1.09- \\
4.590 \\
\end{array}$ & $0.023^{*}$ & 2.03 & $\begin{array}{c}0.99- \\
4.19 \\
\end{array}$ & 0.055 & 1.30 & $\begin{array}{c}0.49- \\
3.45 \\
\end{array}$ & 0.604 \\
\hline & KIF21A WAI & Low & 0.49 & $\begin{array}{c}0.26- \\
0.93 \\
\end{array}$ & $0.025^{*}$ & 0.52 & $\begin{array}{c}0.27- \\
1.01 \\
\end{array}$ & $0.049 *$ & 0.37 & $\begin{array}{c}0.13- \\
1.04 \\
\end{array}$ & $0.048^{*}$ \\
\hline \multirow{5}{*}{$\begin{array}{l}\text { Disease- } \\
\text { free } \\
\text { survival }\end{array}$} & $\begin{array}{c}\text { Tumour } \\
\text { Size }\end{array}$ & $\leq 20 \mathrm{~mm}$ & 1.59 & $\begin{array}{c}1.01- \\
2.50 \\
\end{array}$ & $0.042 *$ & 1.21 & $\begin{array}{c}0.72- \\
2.03 \\
\end{array}$ & 0.477 & 1.29 & $\begin{array}{c}0.77- \\
2.14 \\
\end{array}$ & 0.335 \\
\hline & $\begin{array}{l}\text { Lymph Node } \\
\text { Involvement }\end{array}$ & No & 1.83 & $\begin{array}{c}1.16- \\
2.88\end{array}$ & $0.008^{* *}$ & 1.44 & $\begin{array}{c}1.18- \\
1.75\end{array}$ & $0.001 * *$ & 1.87 & $\begin{array}{c}1.17- \\
2.98\end{array}$ & $0.009 * *$ \\
\hline & $\begin{array}{l}\text { Histological } \\
\text { Grade }\end{array}$ & Low $^{b}$ & 1.53 & $\begin{array}{c}1.13- \\
2.07\end{array}$ & $0.021 *$ & 1.22 & $\begin{array}{c}0.86- \\
1.74\end{array}$ & 0.261 & 1.30 & $\begin{array}{c}0.92- \\
1.83\end{array}$ & 0.142 \\
\hline & ER & Negative & 0.50 & $\begin{array}{c}0.33- \\
0.74\end{array}$ & $0.001 * *$ & 0.47 & $\begin{array}{c}0.30- \\
0.73\end{array}$ & $0.001 * *$ & 0.56 & $\begin{array}{c}0.29- \\
1.07\end{array}$ & $0.001 * *$ \\
\hline & KIF21A WAI & Low & 0.75 & $\begin{array}{c}0.49- \\
1.15\end{array}$ & 0.187 & - & - & - & 0.47 & $\begin{array}{c}0.30- \\
0.73\end{array}$ & 0.080 \\
\hline
\end{tabular}

recurrence (DFS timeline), while censored cases represent patients who either did not experience an event during the entire follow-up period, or who withdrew from the study during the follow-up period without experiencing an event. $* \log$-rank $p<0.05$.

\section{Table 7. Univariate (Kaplan-Meier) and multivariate (Cox proportional hazards} regression) analysis of cause-specific survival in breast IDC patients. Abbreviations: HR: hazard ratio; CI: confidence interval; ER: oestrogen receptor. ${ }^{a}$ Reference groups $(\mathrm{HR}=1)$ were used as the denominator in hazard ratio calculations; ${ }^{b}$ Histological grades 1 and 2 were binned into "low" grade, while "high" is classified as grade 3; " Kaplan-Meier univariate analysis performed using the log-rank (Mantel-Cox) test; ${ }^{\mathrm{d}}$ Model A: Cox proportional hazards model including only significant $(\mathrm{p}<0.05)$ variables identified from the KaplanMeier univariate analysis; ${ }^{\mathrm{e}}$ Model B: Cox proportional hazards model including all variables. $* \mathrm{p}<0.05, * * \mathrm{p}<0.01$. 


\section{FIGURE LEGENDS}

Figure 1. KIF21A silencing efficiencies. A,B) qRT-PCR analysis of KIF21A silencing using two siRNA sequences, siKIF21A-1 and siKIF21A-2, in MCF-7 (A) and MDA-MB-231 (B) cells showed a reduction in KIF21A mRNA expression upon silencing. C,D) Western blot protein band densitometry showed a significant reduction in the optical density of KIF21A protein bands in silenced cells for both cell lines. All protein densities from silenced cells were normalised against $\beta$-actin. For all figures: scrambled siRNA was used as the negative control. Values are mean \pm SEM. $\mathrm{n}=3$ for each group, $* \mathrm{p}<0.05, * * \mathrm{p}<0.01, * * *$ $\mathrm{p}<0.001$ (One-way ANOVA with Tukey's multiple comparisons post-hoc test).

Figure 2. Transwell migration assays of MCF-7 and MDA-MB-231 cells following KIF21A silencing. $(A, C)$ There was a significant decrease in migrated MCF-7 cells and MDA-MB-231 cells following KIF21A silencing for both silenced groups. (B,D) Representative photomicrographs (10x magnification) of cell migration in MCF-7 cells and MDA-MB-231 cells. For all figures: values are mean \pm SEM, $\mathrm{n}=3$ for each group, ${ }^{* *} \mathrm{p}<$ $0.01, * * * \mathrm{p}<0.001, * * * * \mathrm{p}<0.0001$ (One-way ANOVA with Tukey's multiple comparisons post-hoc test). Scale bars represent $100 \mu \mathrm{m}$.

Figure 3. Matrigel invasion assays of MCF-7 and MDA-MB-231 cells following KIF21A silencing. $(A, C)$ There was a significant decrease in invasive MCF-7 cells and MDA-MB231 cells following KIF21A silencing for both silenced groups. (B,D) Representative photomicrographs (10x magnification) of cell invasion in MCF-7 cells and MDA-MB-231 cells. For all figures: values are mean \pm SEM, $\mathrm{n}=3$ for each group, $* \mathrm{p}<0.05, * * \mathrm{p}<0.01$, $* * * \mathrm{p}<0.001, * * * * \mathrm{p}<0.0001$ (One-way ANOVA with Tukey's multiple comparisons posthoc test). Scale bars represent $100 \mu \mathrm{m}$.

Figure 4. Cell proliferation and adhesion assays in MCF-7 and MDA-MB-231 cells following KIF21A silencing. (A,B) Serum-starved proliferation assay of MCF-7 and MDAMB-231 cells following KIF21A silencing. There were no significant differences observed in cell proliferation following KIF21A silencing for both cell lines. (C,D,E,F) Adhesion assays of MCF-7 and MDA-MB-231 cells following KIF21A silencing. For all figures: absorbance (of formazan) was measured at $490 \mathrm{~nm}$ and indicates the relative percentage of live cells; 
values are mean $\pm \mathrm{SEM} ; \mathrm{n}=3$ (proliferation assays) or 7 (adhesion assays) for each group, * $\mathrm{p}<0.05$ (One-way ANOVA with Tukey's multiple comparisons post-hoc test).

Figure 5. $(A, B, C)$ Representative photomicrographs of KIF21A immunoreactivity in breast IDC tissue. Staining was predominately localised to the epithelial nucleus of (A) tumour cells and (B) adjacent normal tissue, while cytoplasmic staining was rare. (C) Negative control slide. Scale bars represent $50 \mu \mathrm{m}$. All photomicrographs are at 40x magnification. (D) There were no significant differences in KIF21A protein expression between breast IDC tumour tissues and adjacent normal tissues, as measured by IHC. Values are mean WAI \pm SEM. $\mathrm{n}=$ 287 (263 tumour, 24 normal) (Mann-Whitney test). Abbreviations: WAI: Weighted Average Intensity.

Figure 6. Kaplan-Meier curves for overall cause-specific survival rate (A), cause-specific survival rate after recurrence (B), and disease-free survival (C). KIF21A protein levels in the epithelial nuclei of tumour cells showed prognostic roles in survival $(A, B)$, but not recurrence (C). Patients with low KIF21A expression in breast cancer tissue had significantly shorter survival than those with high KIF21A expression. 


\section{FIGURES}

\section{Figure 1.}

(A) KIF21A Gene Expression in MCF-7

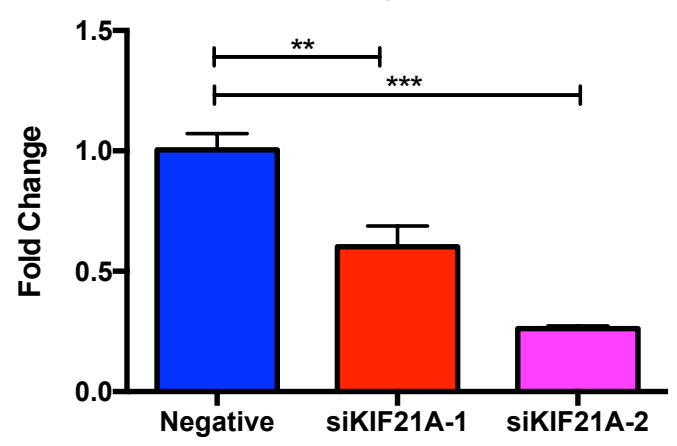

(B)

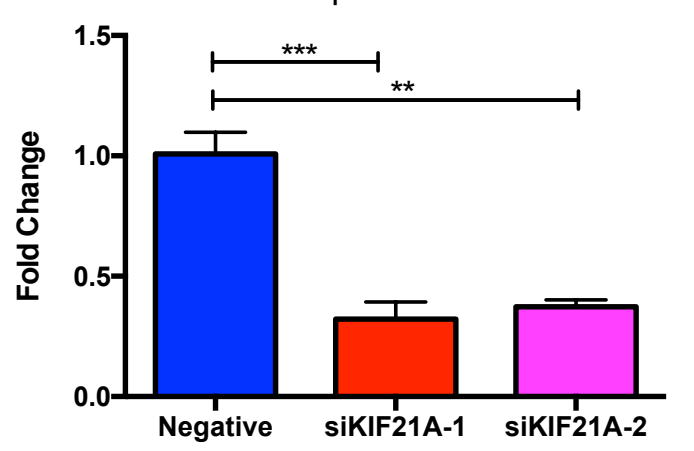

(C) KIF21A Protein Expression in MCF-7

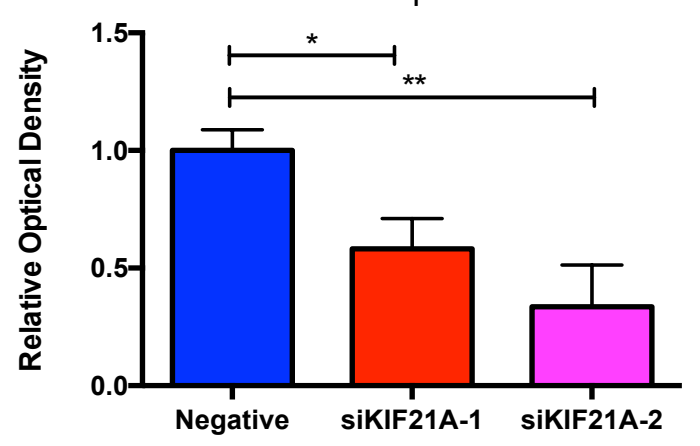

KIF21A

Negative siKIF21A-1 siKIF21A-2

$\beta$-actin

186 kDa

42kDa

(D)

KIF21A Protein Expression in MDA-MB-231

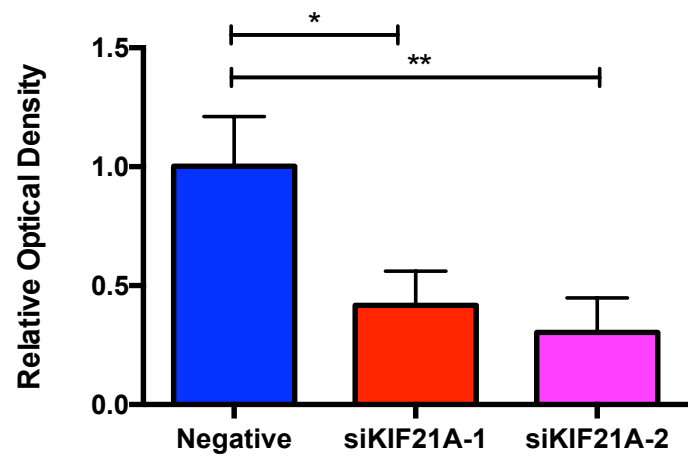

KIF21A

Negative siKIF21A-1 siKIF21A-2

$\beta$-actin

$186 \mathrm{kDa}$

$42 \mathrm{kDa}$ 


\section{Figure 2.}

(A)

Migration Assay in MCF-7 Cells

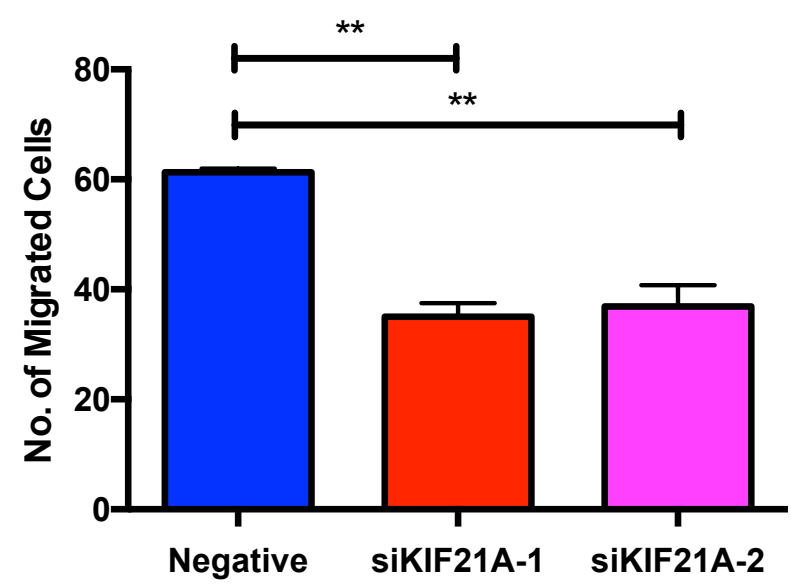

(C)

Migration Assay in MDA-MB-231 Cells

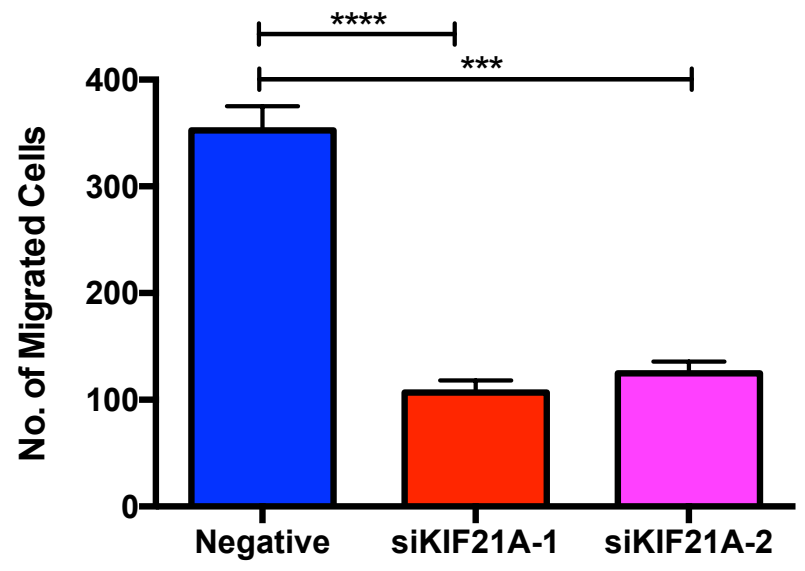

(B)
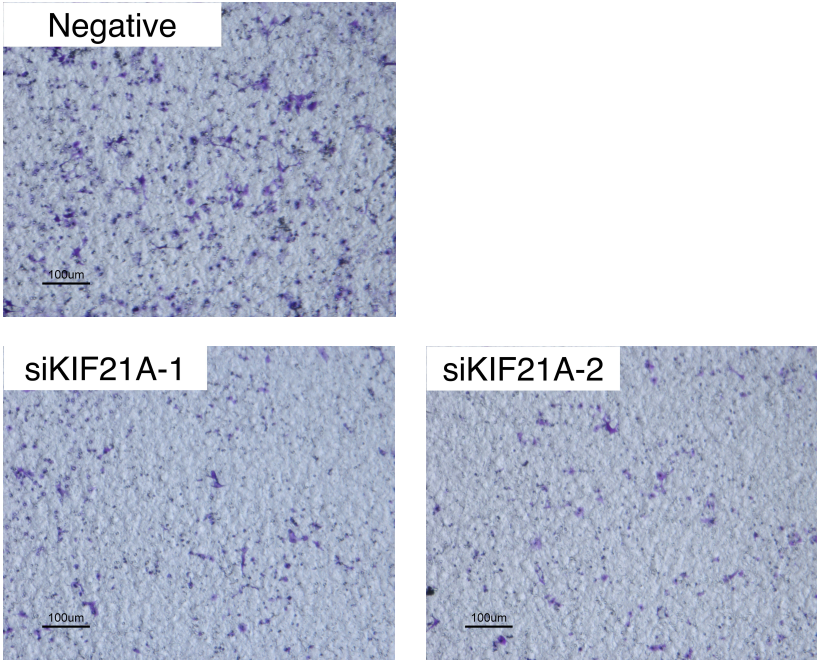

(D)
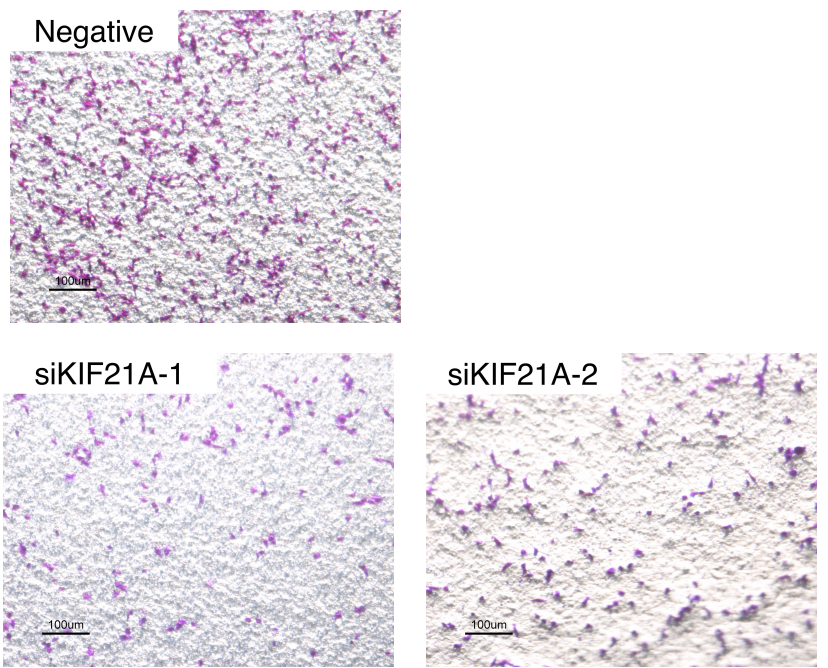


\section{Figure 3.}

(A)

Invasion Assay in MCF-7 Cells

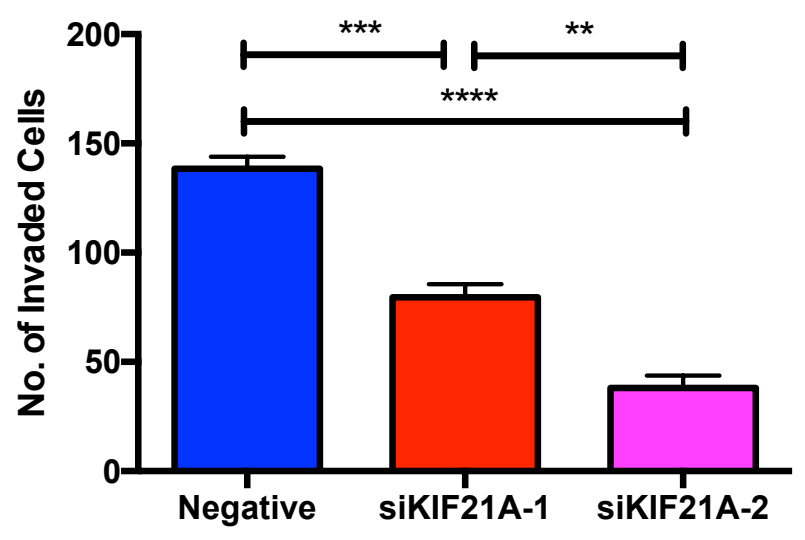

(C)

Invasion Assay in MDA-MB-231 Cells

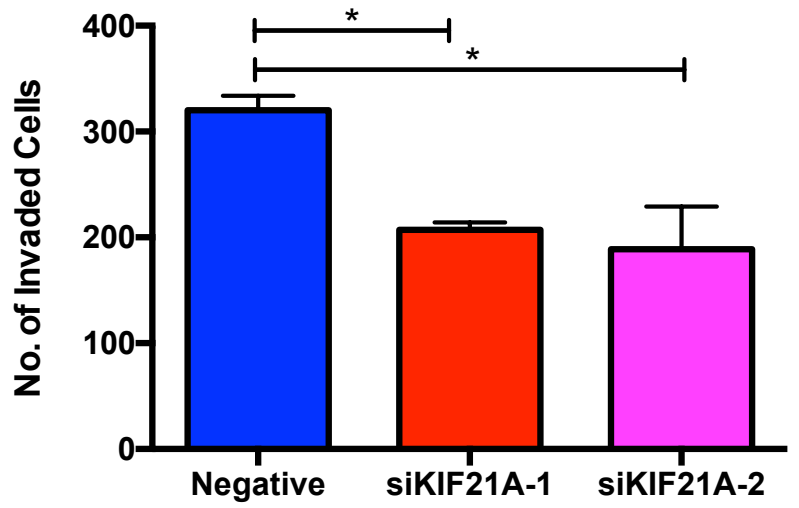

(B)
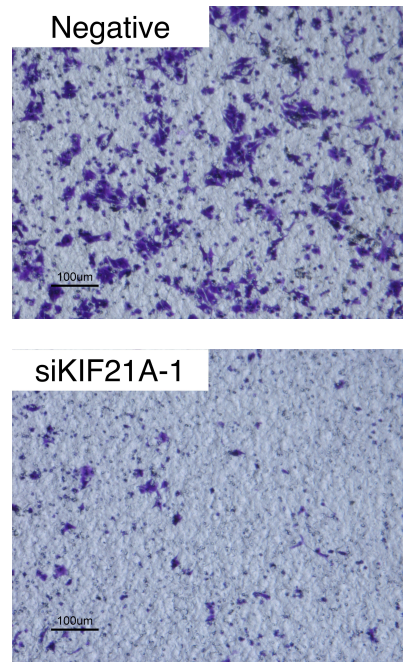

siKIF21A-2

Negative

(D)
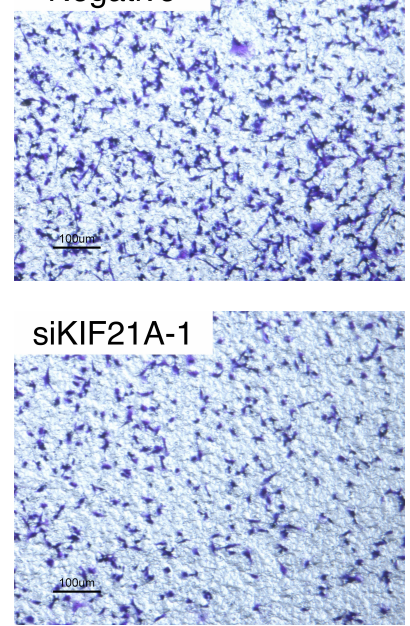

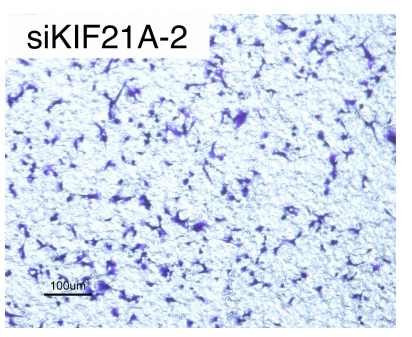


Figure 4.

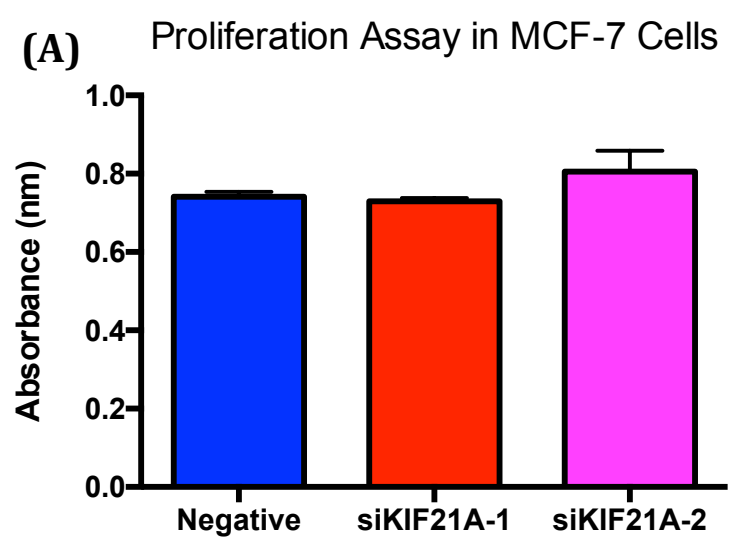

(C)

Collagen Adhesion Assay in MCF-7 Cells

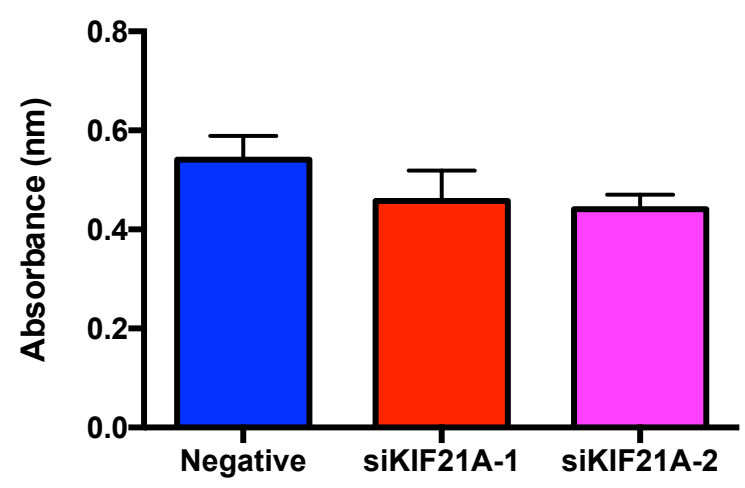

(E)

Collagen Adhesion Assay in MDA-MB-231 Cells

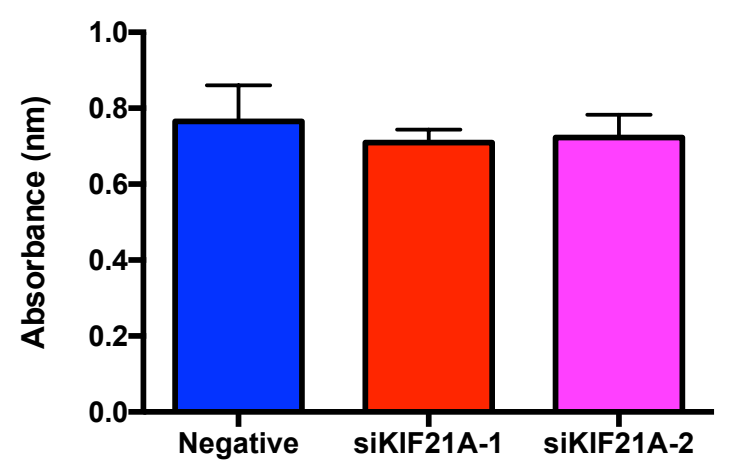

(B) Proliferation Assay in MDA-MB-231 Cells

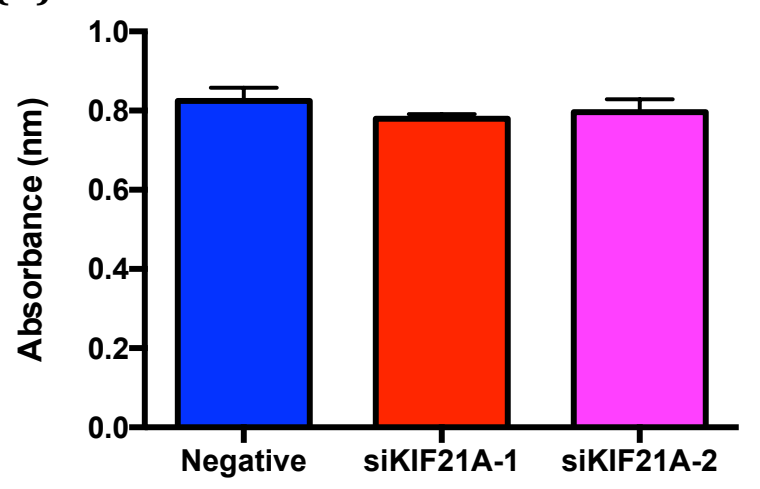

(D)

Fibronectin Adhesion Assay in MCF-7 Cells

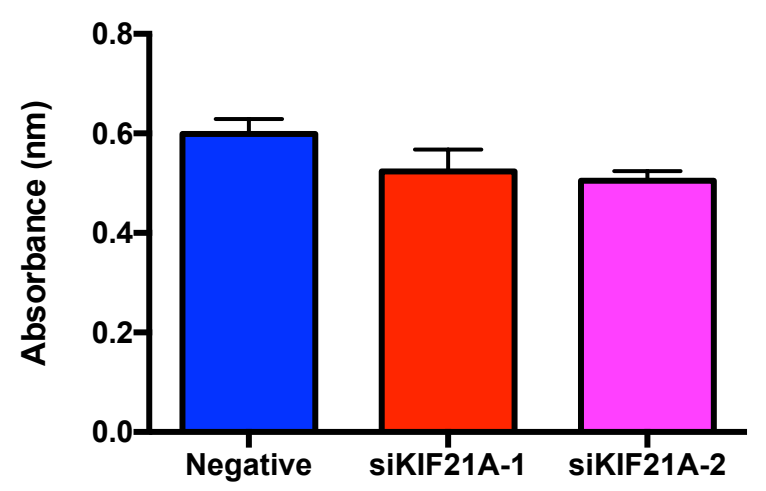

(F)

Fibronectin Adhesion Assay in MDA-MB-231

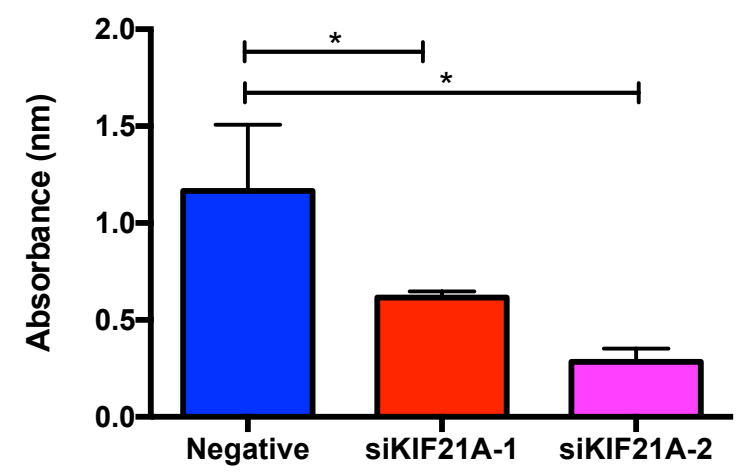


bioRxiv preprint doi: https://doi.org/10.1101/093047; this version posted December 10, 2016. The copyright holder for this preprint (which was not certified by peer review) is the author/funder, who has granted bioRxiv a license to display the preprint in perpetuity. It is made available under aCC-BY-NC 4.0 International license.

\section{Figure 5.}
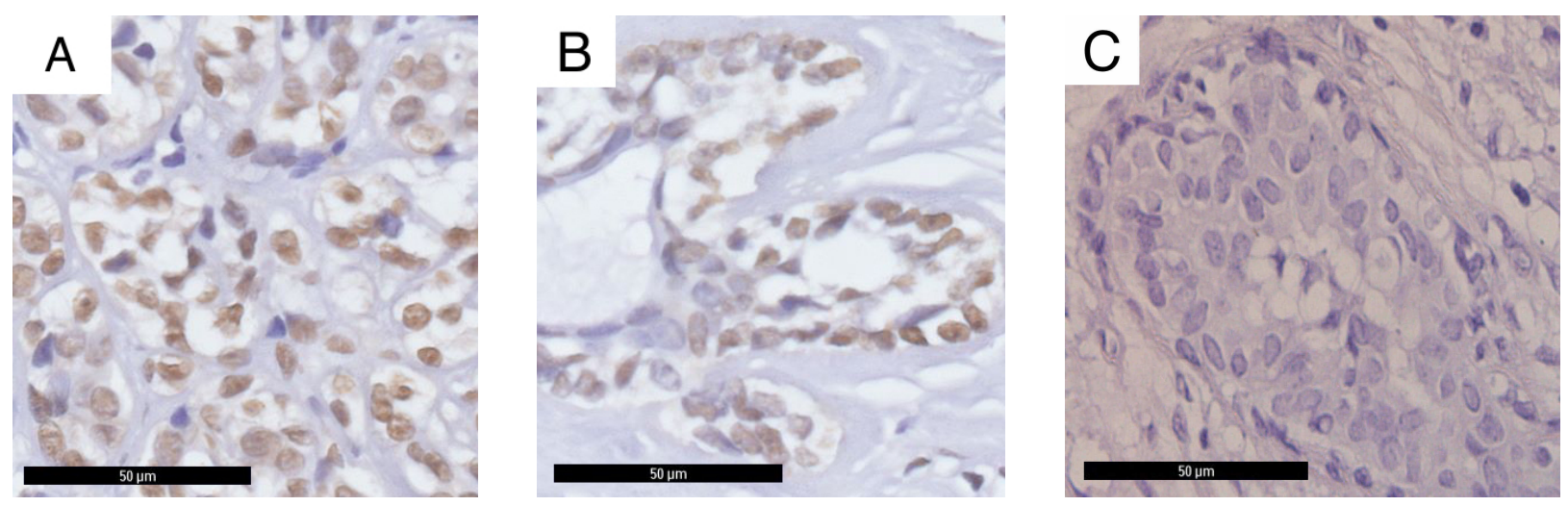

D KIF21A Expression in Nucleus

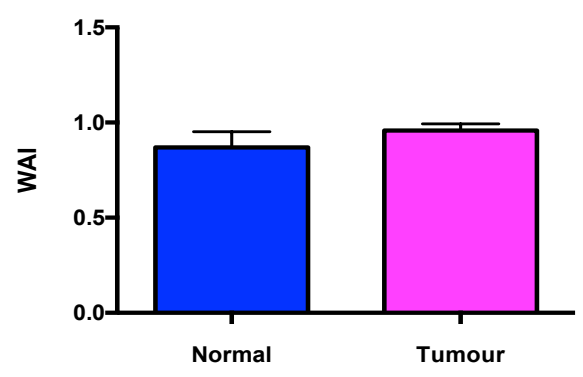




\section{Figure 6.}

\section{(A) Overall Survival}

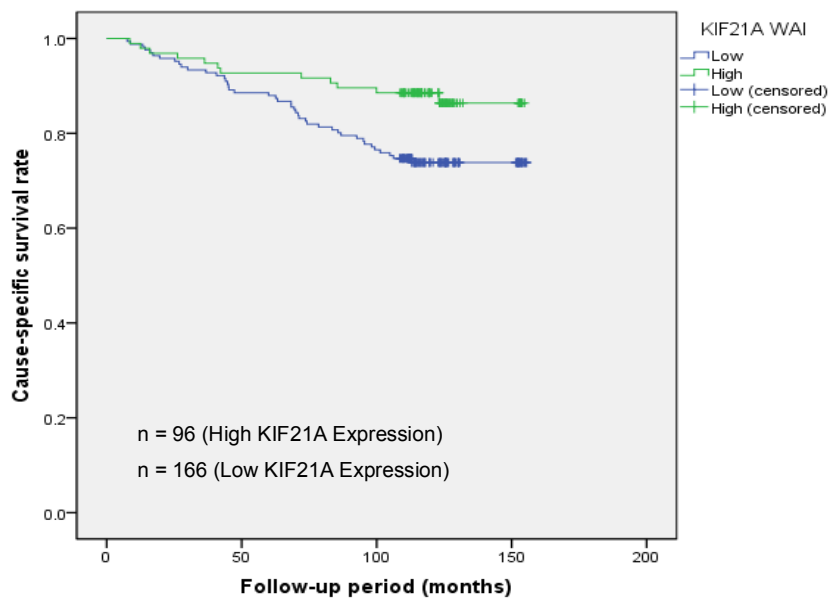

(C) Disease-Free Survival

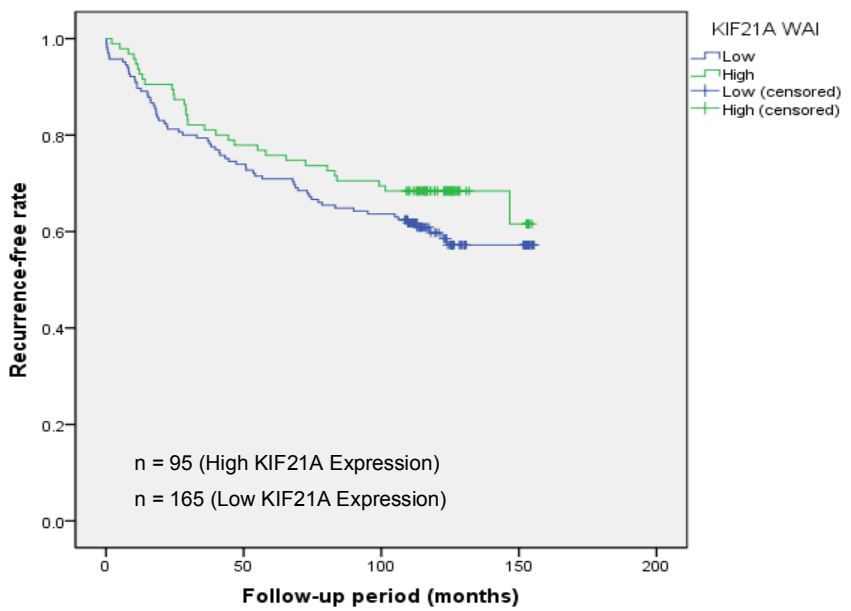

(B) Survival After Recurrence

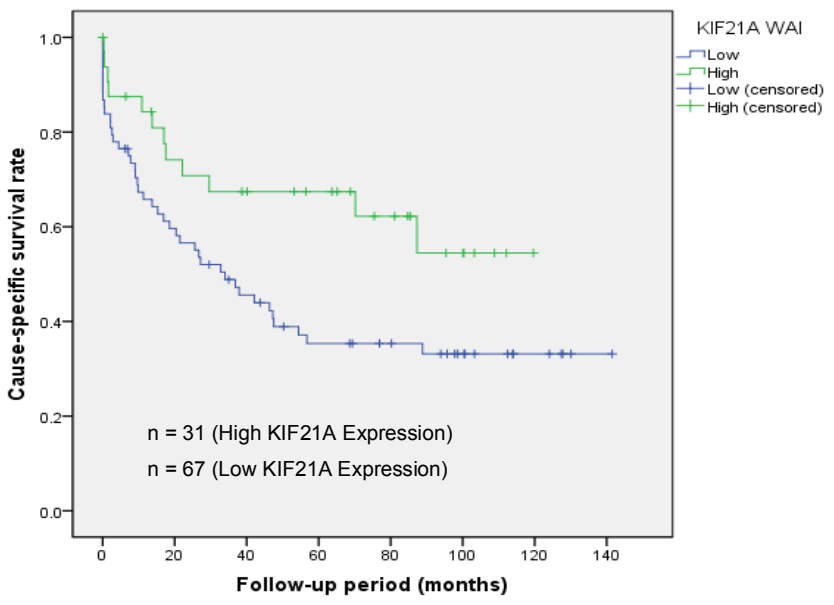




\section{REFERENCES}

1. Ferlay J, Soerjomataram I, Ervik M, Dikshit R, Eser S, Mathers C, et al. GLOBOCAN 2012 v1 .0, Cancer Incidence and Mortality Worldwide: IARC CancerBase No. 11 [Internet]. Lyon, France: International Agency for Research on Cancer; 2013. Available from: http://globocan.iarc.fr, accessed on 01/09/2015.

\section{Liu X, Gong H, Huang K.}

Oncogenic role of kinesin proteins and targeting kinesin therapy. Cancer Sci. 2013 Jun;104(6):651-6.

3. Vale RD, Reese TS, Sheetz MP. Identification of a novel force-generating protein, kinesin, involved in microtubule-based motility. Cell. 1985 Aug;42(1):39-50.

4. Miki H, Setou M, Kaneshiro, Hirokawa. All kinesin superfamily protein, KIF, genes in mouse and human. Proc Natl Acad Sci USA. 2001 Jun 19;98(13):7004-11.

5. Lawrence CJ, Dawe RK, Christie KR, Cleveland DW, Dawson SC, Endow S, et al. A standardized kinesin nomenclature. J Cell Biol. 2004 Oct 11;167(1):19-22.

6. Diefenbach RJ, Mackay JP, Armati PJ, Cunningham AL. The C-terminal region of the stalk domain of ubiquitous human kinesin heavy chain contains the binding site for kinesin light chain. Biochemistry. 1998;37(1):16663-70.

7. Goldstein LS, Philp AV. The road less traveled: emerging principles of kinesin motor utilization. Annu Rev Cell Dev Biol. 1999;15(2): 141-83.

8. Castillo A, Morse HC, Godfrey VL, Naeem R, Justice MJ. Overexpression of Eg5 causes genomic instability and tumour formation in mice. Cancer Res. 2007;67(21):10138-47.

9. Wordeman L. How kinesin motor proteins drive mitotic spindle function: lessons from molecular assays. Semin Cell Dev Biol 2010;21(3):260-8.

10. Carleton M, Mao M, Biery M, Warrener P, Kim S, Buser C, et al. RNA interferencemediated silencing of mitotic kinesin KIF14 disrupts cell cycle progression and induces cytokinesis failure. Mol Cell Biol. 2006 May;26(10):3853-63. 
11. Molina I, Baars S, Brill JA, Hales KG, Fuller MT, Ripoll P. A chromatin-associated kinesin-related protein required for normal mitotic chromosome segregation in Drosophila. $\mathrm{J}$ Cell Biol. 1997 Dec 15;139(6):1361-71.

12. Oki E, Hisamatsu Y, Ando K, Saeki H, Kakeji Y, Maehara Y. Clinical aspect and molecular mechanism of DNA aneuploidy in gastric cancers. $\mathrm{J}$

Gastroenterol 2012;47(4):351-8.

13. Wu G, Zhou L, Khidr L, Guo XE, Kim W, Lee YM, et al. A novel role of the chromokinesin KIF4A in DNA damage response. Cell Cycle. 2008;7(13):2013-2020.

14. Mazumdar M, Lee JH, Sengupta K, Ried T, Rane S, Misteli T.

Tumor formation via loss of a molecular motor protein. Curr Biol. 2006 Aug 8;16(15):155964.

15. Corson TW. Gallie BL. KIF14 mRNA expression is a predictor of grade and outcome in breast cancer. Int J Cancer. 2006 Sep 1;119(5):1088-94.

16. Sanhaji M, Friel CT, Wordeman L, Louwen F, Yuan J. Mitotic centromere-associated kinesin (MCAK): a potential cancer drug target. Oncotarget. 2011 Dec;2(12):935-47.

17. Nishidate T, Katagiri T, Lin ML, Mano Y, Miki Y, Kasumi F, et al. Genome-wide geneexpression profiles of breast-cancer cells purified with laser microbeam microdissection: identification of genes associated with progression and metastasis. Int J Oncol. 2004 Oct;25(4):797-819.

18. Shimo A, Tanikawa C, Nishidate T, Lin ML, Matsudi K, Park JH, et al. Involvement of kinesin family member $2 \mathrm{C} /$ mitotic centromere-associated kinesin overexpression in mammary carcinogenesis. Cancer Sci. 2008 Jan;99(1):62-70.

19. De S Cipriano R, Cipriano R, Jackson MW, Stark GR. Overexpression of kinesins mediates docetaxel resistance in breast cancer cells. Cancer Res. 2009 Oct;69(20):8035-42

20. Tan MH, De S, Bebek G, Orloff MS, Wesolowski R, Downs-Kelly E, et al. Specific kinesin expression profiles associated with taxane resistance in basal-like breast cancer.Breast Cancer Res Treat. 2012 Feb;131(3):849-58. 
21. Ganguly A, Yang H, Cabral F. Overexpression of mitotic centromere-associated kinesin stimulates microtubule detachment and confers resistance to paclitaxel. Mol Cancer Ther. 2011 Jun;10(6):929-37.

22. Groth-Pedersen L, Aits S, Corcelle-Termeau E, Petersen NH, Nylandsted J, Jäättelä M. Identification of cytoskeleton-associated proteins essential for lysosomal stability and survival of human cancer cells. PLoS One. 2012;7(10):e45381.

23. Jimbo T, Kawasaki Y, Koyama R, Sato R, Takada S, Haraguchi K, et al. Identification of a link between the tumour suppressor APC and the kinesin superfamily. Nat Cell Biol. 2002 Apr;4(4):323-7.

24. Wang F, Lin SL. Knockdown of kinesin KIF11 abrogates directed migration in response to epidermal growth factor-mediated chemotaxis. Biochem Biophys Res Commun. 2014 Sep;452(3):642-8.

25. Ahmed SM, Theriault BL, Uppalapati M, Chiu CW, Gallie BL, Sidhu SS, et al. KIF14 negatively regulates Rap1a-Radil signaling during breast cancer progression. J Cell Biol. 2012 Dec 10;199(6):951-67.

26. Wang J, Ma S, Ma R, Qu X, Liu W, Ly C, et al. KIF2A silencing inhibits the proliferation and migration of breast cancer cells and correlates with unfavorable prognosis in breast cancer. BMC Cancer. 2014 Jun 21;14:461.

27. Zhang C, Zhu C, Chen H, Li L, Guo L, Jiang W, et al. Kif18A is involved in human breast carcinogenesis. Carcinogenesis. 2010 Sep;31(9):1676-84.

28. Yu Y, Wang XY, Sun L, Wang YL, Wan YF, Li XQ, et al. Inhibition of KIF22 suppresses cancer cell proliferation by delaying mitotic exit through upregulating CDC25C expression. Carcinogenesis. 2014 Jun;35(6):1416-25.

29. Li G, Luna C, Qiu J, Epstein DL, Gonzalez P. Targeting of Integrin $\beta 1$ and Kinesin $2 \alpha$ by MicroRNA 183. J Biol Chem. 2010 Feb 19; 285(8): 5461-5471.

30. Yoon JR, Whipple RA, Balzer EM, Cho EH, Matrone MA, Peckham M, et al. Local anesthetics inhibit kinesin motility and microtentacle protrusions in human epithelial and breast tumor cells. Breast Cancer Res Treat. 2011 Oct;129(3):691-701. 
31. Wakefield LM, Roberts AB. TGF-beta signaling: positive and negative effects on tumorigenesis. Curr Opin Genet Dev. 2002 Feb;12(1):22-9.

32. Roberts AB, Wakefield LM. The two faces of transforming growth factor beta in carcinogenesis. Proc Natl Acad Sci USA. 2003 Jul 22;100(15):8621-3.

33. de la Iglesia N, Konopka G, Puram SV, Chan JA, Bachoo RM, You MJ, et al. Identification of a PTEN-regulated STAT3 brain tumor suppressor pathway. Genes Dev. 2008 Feb 15;22(4):449-62.

34. Hung PF, Hong TM, Hsu YC, Chen HY, Chang YL, Wu CT, et al. The motor protein KIF14 inhibits tumor growth and cancer metastasis in lung adenocarcinoma. PLoS One. 2013;8(4):e61664.

35. Shen X, Meza-Carmen V, Puxeddu E, Wang G, Moss J, Vaughan M. Interaction of brefeldin A-inhibited guanine nucleotide-exchange protein (BIG) 1 and kinesin motor protein KIF21A. Proc Natl Acad Sci USA. 2008 Dec 2; 105(48):18788-93.

36. Boal F, Stephens DJ. Specific functions of BIG1 and BIG2 in endomembrane organization. PLoS One. 2010 Mar 25; 5(3):e9898.

37. Kakinuma N, Kiyama R. A major mutation of KIF21A associated with congenital fibrosis of the extraocular muscles type 1 (CFEOM1) enhances translocation of Kank1 to the membrane. Biochem Biophys Res Commun. 2009 Sep 4; 386(4):639-44.

38. Li CC, Kuo JC, Waterman CM, Kiyama R, Moss J, Vaughan M. Effects of brefeldin Ainhibited guanine nucleotide-exchange (BIG) 1 and KANK1 proteins on cell polarity and directed migration during wound healing. Proc Natl Acad Sci U S A. 2011 Nov 29;108(48):19228-33.

39. Etienne-Manneville S. Cdc42--the centre of polarity. J Cell Sci. 2004 Mar 15;117(8):1291-300.

40. Etienne-Manneville S, Hall A. Cell polarity: Par6, aPKC and cytoskeletal crosstalk. Curr Opin Cell Biol. 2003 Feb;15(1):67-72.

41. Narod SA. Tumour size predicts long-term survival among women with lymph nodepositive breast cancer. Curr Oncol. 2012 Oct; 19(5):249-253. 
42. Zou JX, Duan Z, Wang J, Sokolov A, Xu J, Chen CZ, Li JJ, Chen HW. Kinesin family deregulation coordinated by bromodomain protein ANCCA and histone methyltransferase MLL for breast cancer cell growth, survival, and tamoxifen resistance. Mol Cancer Res. 2014 Apr;12(4):539-49.

43. Wang J, Ma S, Ma R, Qu X, Liu W, Ly C, et al. KIF2A silencing inhibits the proliferation and migration of breast cancer cells and correlates with unfavorable prognosis in breast cancer. BMC Cancer. 2014 Jun 21;14:461.

44. Wang C, Wang C, Wei Z, Li Y, Wang W, Li X, et al. Suppression of motor protein KIF3C expression inhibits tumor growth and metastasis in breast cancer by inhibiting TGF- $\beta$ signaling. Cancer Lett. 2015 Nov 1;368(1):105-14.

45. Wang Q, Zhao ZB, Wang G, Hui Z, Ming-Hua W, Jun-Feng P, et al. High expression of KIF26B in breast cancer associates with poor prognosis. PLoS One. 2013;8(4):e61640.

46. Gao J, Sai N, Wang C, Sheng X, Shao Q, Zhou C, et al. Overexpression of chromokinesin KIF4 inhibits proliferation of human gastric carcinoma cells both in vitro and in vivo.

Tumour Biol. 2011 Feb;32(1):53-61.

47. Massague J. G1 cell cycle control and cancer. Nature. 2004;432:298-306.

48. Bakhoum SF, Compton DA. Chromosomal instability and cancer: a complex relationship with therapeutic potential. J Clin Invest. 2012 Apr;122(4):1138-43.

49. Chan JY. A clinical overview of centrosome amplification in human cancers. Int J Biol Sci. 2011;7(8):1122-44.

50. McGranahan N, Burrell RA, Endesfelder D, Novelli MR, Swanton C. Cancer chromosomal instability: therapeutic and diagnostic challenges. EMBO Rep. 2012 Jun 1;13(6):528-38.

51. Pfau SJ, Amon A. Chromosomal instability and aneuploidy in cancer: from yeast to man. EMBO Rep. 2012 Jun 1;13(6):515-27. 